\title{
Materials Combustion Testing and Combustion Product Sensor Evaluations in FY12
}

\author{
Marit E. Meyer \\ NASA John H. Glenn Research Center \\ Cleveland, $\mathrm{OH} 44135$ \\ Paul D. Mudgett \\ NASA Johnson Space Flight Center \\ Houston, TX \\ Steven D. Hornung and Mark B. McClure \\ NASA White Sands Test Facility \\ Las Cruces, NM \\ Jeffrey S. Pilgrim \\ Vista Photonics, Inc. \\ Santa Fe, NM \\ Victoria Bryg \\ National Center for Space Exploration Research \\ Cleveland, $\mathrm{OH} 44135$ \\ Darby Makel \\ Makel Engineering \\ Chico, CA 95973 \\ Gary A. Ruff and Gary Hunter \\ NASA John H. Glenn Research Center \\ Cleveland, $\mathrm{OH} 44135$
}

NASA Centers continue to collaborate to characterize the chemical species and smoke particles generated by the combustion of current space-rated non-metallic materials including fluoropolymers. This paper describes the results of tests conducted February through September 2012 to identify optimal chemical markers both for augmenting particle-based fire detection methods and for monitoring the post-fire cleanup phase in human spacecraft. These studies follow up on testing conducted in August 2010 and reported at ICES 2011. The tests were conducted at the NASA White Sands Test Facility in a custom glove box designed for burning fractional gram quantities of materials under varying heating profiles. The $623 \mathrm{~L}$ chamber was heavily instrumented to quantify organics (gas chromatography/mass spectrometry), inorganics by water extraction followed by ion chromatography, and select species by various individual commercially-available sensors. Evaluating new technologies for measuring carbon monoxide, hydrogen cyanide, hydrogen fluoride, hydrogen chloride and other species of interest was a key objective of the test. Some of these sensors were located inside the glovebox near the fire source to avoid losses through the sampling lines; the rest were located just outside the glovebox. Instruments for smoke particle characterization included a Tapered Element Oscillating Microbalance Personal Dust Monitor (TEOM PDM) and a TSI Dust 
Trak DRX to measure particle mass concentration, a TSI PTrak for number concentration and a thermal precipitator for collection of particles for microscopic analysis. Materials studied included Nomex ${ }^{\circledR}$, M22759 wire insulation, granulated circuit board, polyvinyl chloride (PVC), Polytetrafluoroethylene (PTFE), Kapton ${ }^{\circledR}$, and mixtures of PTFE and Kapton ${ }^{\circledR}$. Furnace temperatures ranged from $340^{\circ}$ to $640^{\circ} \mathrm{C}$, focusing on the smoldering regime. Of particular interest in these tests was confirming burn repeatability and production of acid gases with different fuel mixture compositions, as well as the dependence of aerosol concentrations on temperature.

\section{Introduction}

$\mathrm{N}$ ASA's ongoing collaborative efforts to develop early fire detectors and post-fire cleanup equipment include characterizing the smoke generated by common spacecraft materials. Understanding the most likely gas and aerosol fire signatures on a spacecraft is fundamental to the design of a fire protection system. Initial testing at WSTF in 2010 focused on developing a consistent post-fire challenge for the purpose of requirements definition and qualification of post-fire cleanup protective breathing equipment [1]. Subsequent testing in 2011 added instruments to characterize the smoke aerosol particles as well. Further work took place in 2012 with two additional test campaigns at the NASA White Sands Test Facility (WSTF). Multiple entities participated, bringing newly developed and mature gas sensors and aerosol instruments. These latest testing activities have benefitted from improvements to the test facility itself. Test matrices were broadened with the investigation of new fuels and various fuel preparation methods.

\section{Test Facility and Procedures}

The test facility consists of an exposure chamber, a custom smoke generator, and reference instruments. Several types of fuel samples have been developed and used in this test program as well as specialized test procedures. These are discussed in the following sections as well as the diagnostics specifically included for this test program.

\section{A. Exposure Chamber and Smoke Generator}

An instrumented chamber was developed for this testing. The chamber, shown in Figure 1 has a volume of $623 \mathrm{~L}$ $\left(22 \mathrm{ft}^{3}\right)$ with support plumbing to exhaust the chamber to a roof vent stack, as well as two fans to circulate the chamber atmosphere. The circulation fans are controlled through the data system and used during each test. Tests were conducted in ambient air at 12.4 psia (WSTF ambient atmospheric pressure). The chamber has ports for withdrawing samples and accommodating power and data cables. Figure 2 is a schematic representation of the instrumentation used in the testing.

The smoke generator,also shown in Figure 1, consists of a quartz-lined electrical tube heater with an air supply line that introduces a low flow of air to the hot mixture. This system has been designed so that both flaming and smoldering fires can be simulated. Several different smoldering conditions, which typically have the highest production rate of toxic products, were run in this test by operating the tube heater at specific set-point temperatures between 350 to $640{ }^{\circ} \mathrm{C}$. In general, these scenarios emulate 1) a low temperature fire that produces a maximum of volatile organic compounds with little thermal oxidation, 2) a higher temperature test where the conditions produce a significant concentration of carbon monoxide (CO), and 3) a condition that produces the worst-case particulate concentration. Flaming conditions are simulated as a variant of the high temperature smoldering challenge where the effluent is intentionally ignited remotely after smoke production is well established. Furnace temperature control was improved for the current testing by adding a feedback temperature controller with a user selectable heating rate. Additional ports were added to improve chamber access and accommodate additional external sensors.

\section{B. Sample Materials and Conditions}

The experimental design has "evolved" somewhat with each test as we learn how to conduct this type of testing in an efficient way. Each test campaign was limited to 1 week, which forced us to be economical in choosing the fuels, parameters and replicates. The week-long tests carried out in 2012 differed from the original test in August 2010 and from each other in several ways. Based on the 2010 results, the fuel mass was standardized at $0.5 \mathrm{~g}$ per burn. A somewhat different set of fuel materials was used in each test, but with significant overlap. For the 
September 2012 test, to enable complete burns, we decided not to pelletize the fuel; rather, loose granulated material was placed carefully on the mica liner and inserted into the oven.
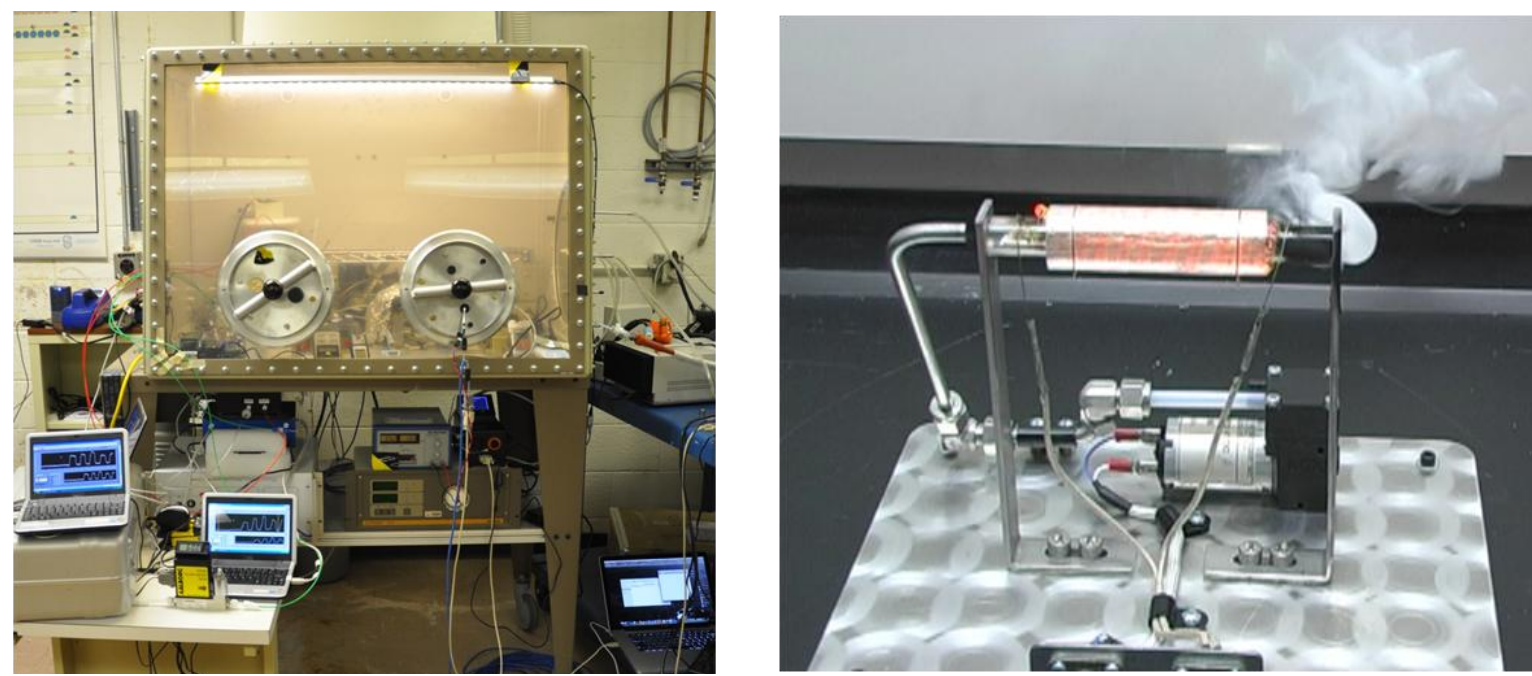

Figure 1. Exposure chamber during September 2012 testing (left), Smoke generator (right).

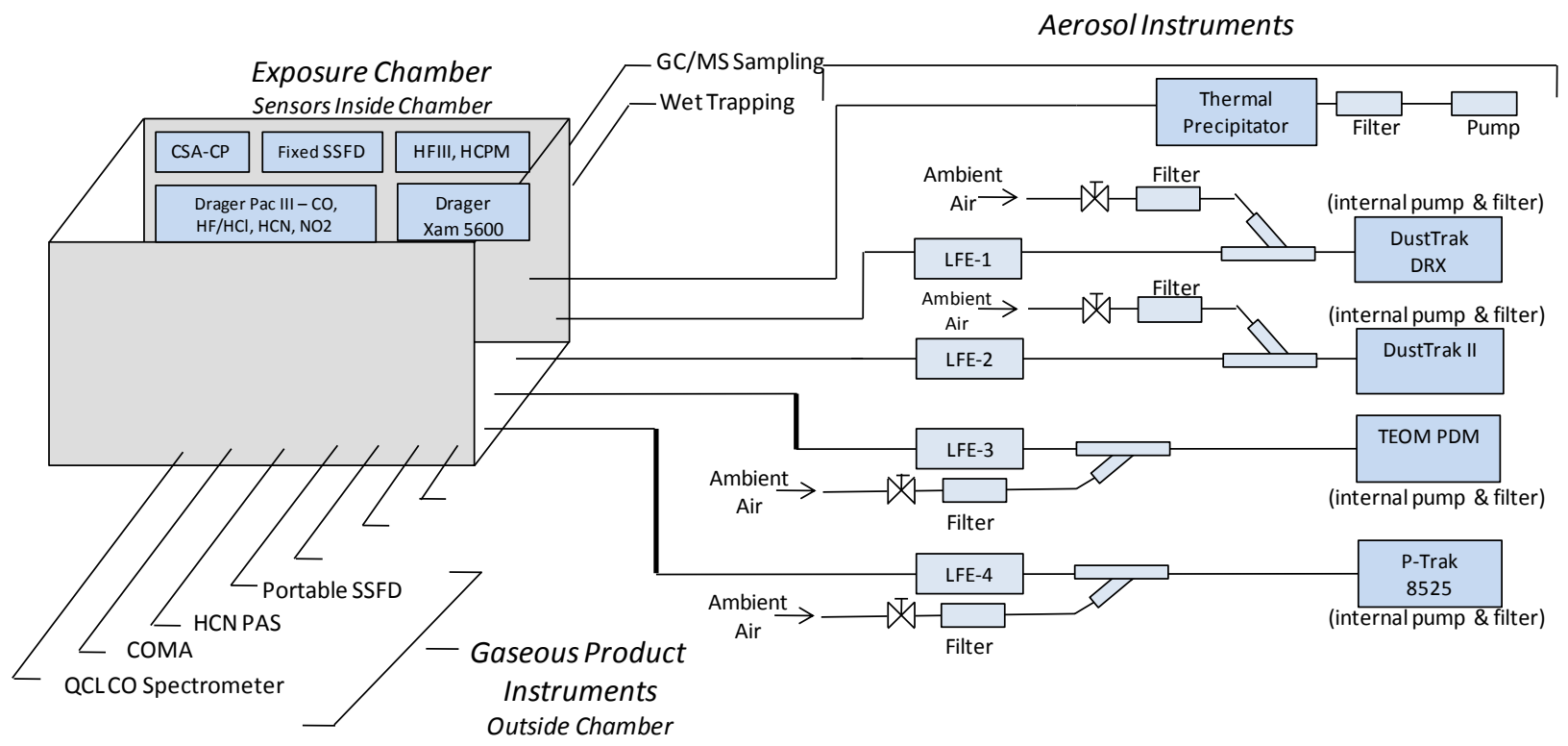

Figure 2. Schematic of instruments placed inside and plumbed to the chamber, including laminar flow elements (LFE) for dilution of aerosol instruments.

Tables 1 and 2 show the test matrices from the two test campaigns in 2012. Differences in the temperatures, materials, number of replicates and total number of runs indicate the evolution of the WSTF testing efforts and emphases. The Standard Mix fuel is a mixture of twelve granulated constituents represented in specific mass fractions down to the hundredth of a gram. Exact proportions and materials are outlined in Reference 2. This material was created as a fire fuel proportionally representative of materials on spacecraft. This fuel was predominantly used in February/March testing and in previous WSTF test campaigns [2]. Materials used for the February/March test are shown in Table 1. The PFPI wire insulation is partially fluorinated polyimide manufactured by TRW. The circuit board was a downgraded flight spare fully populated with certified conformal coating as an example of modern electronics. Materials for the September testing are shown in Figure 3. For the Sep 2012 test, we researched the current spacecraft wire specification and found it to be Mil Spec M22759, produced by using a 
PTFE and polyimide tape wrap process to produce layers over the conductor which are then thermally fused. The insulation was stripped from 12 gauge M22759/86 wire (manufactured by Nexans) in short random lengths, and used as-is without further granulation. The Nomex cloth was scissors cut into 3 to $5 \mathrm{~mm}$ shredded pieces. PTFE granules were made with a rotary shaving device, whereas the PTFE powder was purchased, with a uniform size of $100 \mu \mathrm{m}$. The Kapton pieces were thin strips of film cut into approximately $2 \mathrm{~mm}$ squares. The Kapton film was difficult to shred and required some hand sorting to eliminate larger pieces. The granulated circuit board was made with a rotary grinder and metal portions of the circuit card assembly were avoided during the grinding process and in weighing out the 0.5 gram samples to avoid skewing the weight of the $0.5 \mathrm{~g}$ sample.

Table 1. Feb-Mar 2012 Test Outline (some ignition)

\begin{tabular}{lccccl} 
Material (0.5 g) & Furnace Temp/C & Ignite & Replicates & \# Tests & Notes \\
\hline Standard Mix & $340,440,540,640$ & Yes & $1-2$ & 7 & Granulated, see Reference 2 \\
Granulated Circuit Board & $340,440,540$ & Yes & $2-3$ & 5 & Populated, conformal coated \\
PFPI wire insulation & 540,640 & No & $3-4$ & 7 & 20AWG stripped \\
100\% PTFE & 540,640 & No & $2-3$ & 5 & Granulated \\
100\% Kapton & 540,640 & No & $2-3$ & 5 & Granulated \\
50:50 PTFE/Kapton mix & 540,640 & No & $1-2$ & 3 & Mixtures of above \\
25:75 PTFE/Kapton mix & 540,640 & No & 2 & 4 & \\
75:25 PTFE/Kapton mix & 540,640 & No & $1-2$ & 3 & \\
10:90 PTFE/Kapton mix & 640 & No & 2 & 2 & \\
90:10 PTFE/Kapton mix & 640 & No & 2 & 2 &
\end{tabular}

Table 2. Sep 2012 Test Outline (No ignition)

\begin{tabular}{lcccl} 
Material (0.5g) & Furnace Temp/C & Replicates & \# Tests & Notes \\
\hline Nomex & 640 & 7 & 7 & HT9040, natural, untreated \\
Nexans Wire Insulation & 640 & 6 & 6 & M22759/86 12AWG stripped \\
$100 \%$ PTFE & 640 & 8 & 8 & 4 Granulated \& 4 powdered PTFE \\
$100 \%$ Kapton & 640 & 5 & 5 & Granulated \\
PTFE/Kapton mixes & 640 & $3-4$ & 18 & $10 / 90 ; 90 / 10 ; 25 / 75 ; 75 / 25 ; 50 / 50$ \\
Circuit Board (PCB) & $340,440,540,640$ & 2 & 8 & Granulated \\
PVC & 640 & 1 & 1 & Granulated; for HCl production \\
PCB+PVC & 640 & 3 & 3 & $0.5 \mathrm{~g}$ PCB with 0.05g PVC “std addition" \\
PCB+PVC & 640 & 2 & 2 & $0.5 \mathrm{~g}$ PCB + 0.1g PVC \\
PTFE+PVC & 640 & 1 & 1 & $0.4 \mathrm{~g}$ PTFE + 0.1g PVC
\end{tabular}

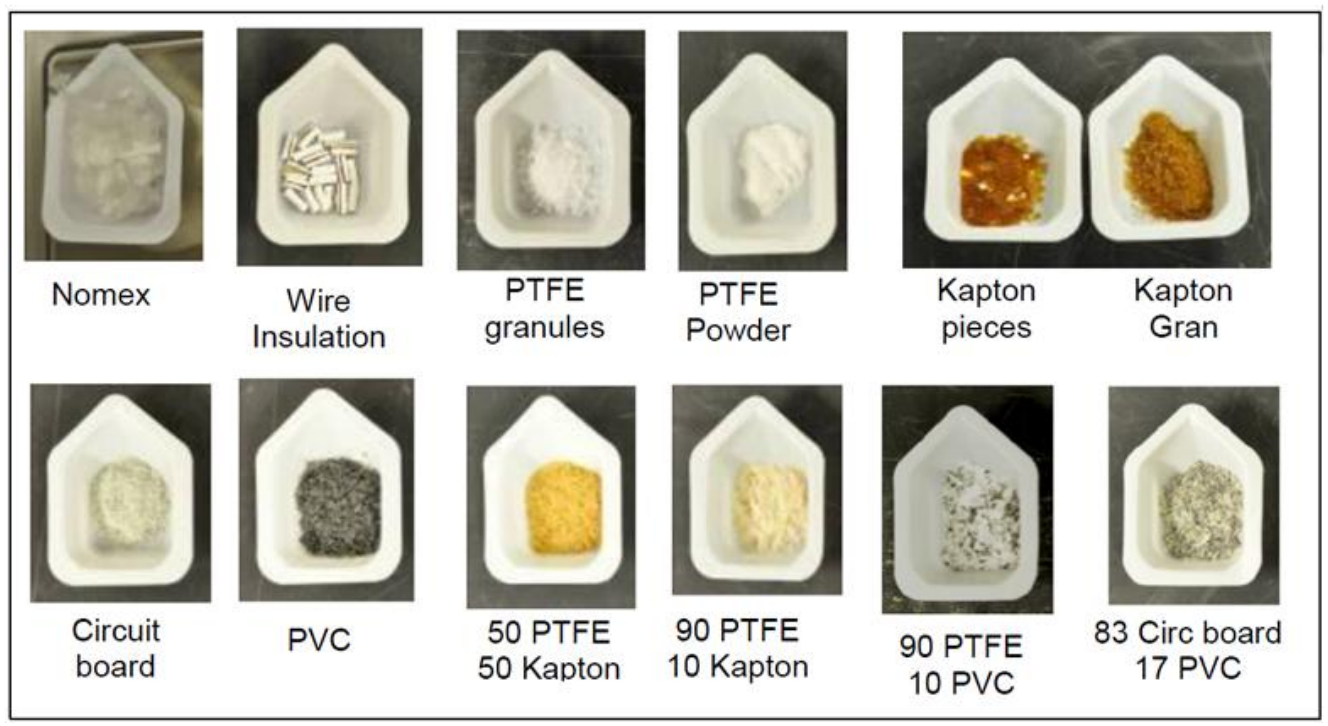

Figure 3. September sample materials before burning.

American Institute of Aeronautics and Astronautics 


\section{Test Procedure}

The sample tube heater near the center of the chamber is controlled by a LabView interface which dictates the temperature ramp duration and magnitude. The test procedure timing is outlined in Table 3. A fan near the rear corner is turned on for approximately 30 seconds after the heater is turned off to provide a uniform concentration inside the test chamber. After mixing, the combustion products are allowed to decay for 5-10 minutes after which the chamber is purged with a vent fan. The front ports are opened to allow fresh lab air to be pulled into the chamber during venting. The time to complete a test, from the chamber sealing until the final venting is approximately 20-30 minutes.

Table 3. Standardized Test Procedure Timing (each run)

\begin{tabular}{|c|l|}
\hline Step & Description \\
\hline 1 & Load fuel, close up chamber, turn off purge vent \\
\hline 2 & Ramp furnace temperature up to target temperature \\
\hline 3 & Turn furnace blower ON once furnace temperature reached (at $\mathrm{t}=3 \mathrm{~min}$ ) \\
\hline 4 & Hold furnace temperature for $\sim$ 4min \\
\hline 5 & Turn off furnace at $\mathrm{t}=7$ min $\&$ stir chamber via muffin fan for $30 \mathrm{sec}$ \\
\hline 6 & 5 to 10 min dwell/natural decay (occasionally longer) \\
\hline 7 & Vent chamber, switch on purge duct fan \\
\hline 8 & Remove and weigh ash \\
\hline
\end{tabular}

\section{Test Instrumentation}

A record number of sensors were incorporated in the testing campaigns of 2012. Table 4 lists each instrument and identifies its core technology. The source of each instrument is either the designer or manufacturer and the sponsoring NASA organization that facilitated participation in the WSTF testing. Not all instruments were present both in February/March and September testing and improvements were made to some in between testing campaigns.

Table 4. Test Instrumentation

\begin{tabular}{|c|c|c|c|}
\hline Instrument & Source & Core Technology & Target Analytes \\
\hline PAS & Vista Photonics/GRC & Photoacoustic TDLS* & $\mathrm{HCN}$ \\
\hline HFIII, HCPM & Vista Photonics/GRC\&JSC & Enhanced TDLS & $\mathrm{HF}, \mathrm{HCl}$ \\
\hline COMA & Vista Photonics/GRC & Multipass TDLS & $\mathrm{CO}$ with $\mathrm{CH} 4$ compensation \\
\hline SSFD Fixed unit & Makel Engineering/GRC & Solid state sensor & $\mathrm{CO}, \mathrm{CO} 2$, hydrocarbons (HC) \\
\hline SSFD Portable unit & Makel Engineering/GRC & Solid state sensor & $\mathrm{CO}, \mathrm{CO} 2$, hydrocarbons (HC) \\
\hline CSA-CP & Industrial Scientific/JSC & Electrochemical cell & $\mathrm{O} 2, \mathrm{CO}, \mathrm{HCN}, \mathrm{HCl}$ \\
\hline Xam-5600 & Draeger/JSC & Electrochemical cell/NDIR & $\mathrm{O} 2, \mathrm{CO}, \mathrm{HCN}, \mathrm{CO} 2$ \\
\hline PacIII & Draeger/WSTF & Electrochemical cell & $\mathrm{CO}, \mathrm{HF} / \mathrm{HCl}, \mathrm{HCN}, \mathrm{NO}_{2}$ \\
\hline Thermal Precipitator & GRC & Particle thermophoresis & Aerosol capture for microscopy \\
\hline TEOM PDM & ThermoFischer/GRC & Gravimetric & Aerosol mass concentration \\
\hline DustTrak DRX & TSI, Inc./GRC & $\begin{array}{l}\text { Laser photometer, with single } \\
\text { particle counting }\end{array}$ & Aerosol mass concentration \\
\hline DustTrak II & TSI, Inc./WSTF & Laser photometer & Aerosol mass concentration \\
\hline P-Trak 8525 & TSI, Inc./WSTF & Condensation/Light Scattering & Ultrafine particle concentration \\
\hline GC/MS** & Hewlett Packard/WSTF & $\begin{array}{l}\text { Gas chromatography/mass } \\
\text { spectrometry }\end{array}$ & Volatile organic compounds \\
\hline Ion Chromatography & WSTF & $\begin{array}{l}\text { Offline IC, wet trap sample } \\
\text { analysis }\end{array}$ & Inorganic anions \\
\hline $\begin{array}{l}\text { Quantum Cascade } \\
\text { Laser Spectrometer*** }\end{array}$ & Port City Instruments/JPL & Multipass TDLS & $\mathrm{CO}$ \\
\hline
\end{tabular}

\section{A. Tunable Diode Laser Spectroscopy based instruments from Vista Photonics}

An improved photo-acoustic (PAS) based HCN sensor was present at both rounds of WSTF testing in 2012. This sensor is superior to the earlier FY2010 PAS instrument which operated at $1531 \mathrm{~nm}$ [3]. That sensor read 
significantly higher HCN levels than other available diagnostics under the test conditions. It appeared that other, as yet unknown, combustion evolved hydrocarbon species were contributing to the HCN measurement. In contrast, the new PAS sensor operates at $2498 \mathrm{~nm}$ where fewer hydrocarbons can interfere with HCN measurement. The PAS gas sensor cell was thermoelectrically heated to a fixed temperature in order to maintain a stable acoustic resonance frequency. The laser diode was simultaneously wavelength modulated and wavelength scanned by injection current over the line center of the gas target absorption feature. The laser wavelength was modulated at the $3 \mathrm{kHz}$ cell resonance frequency. Absorption of laser emission by the target gas is converted to sound occurring at the modulation frequency, which is the natural resonance frequency of the acoustic cell. The cell resonance provides about an order-of-magnitude improvement in sensitivity over non-resonant operation. Measurement precision for $\mathrm{HCN}$ is about 0.3 part-per-million ( $\mathrm{ppm}$ ) with a linear averaging time of 20 seconds. Present testing has shown a much closer correlation with other HCN sensors, indicating that this new wavelength is unaffected by other combustion products.

Earlier PAS combustion measurements at WSTF have shown that optical approaches suffering long sample interaction times are not effective when applied to highly reactive transient evolved combustion species. In contrast, the present employed technique for reactive acid gases utilizes rapid sampling and short sample interaction paths in an SBIR-developed proprietary path length enhanced optical approach combined with wavelength modulation spectroscopy (WMS) and tunable infrared semiconductor laser diodes [4]. Several prototypes have been successfully demonstrated for monitoring hydrogen fluoride (HF) in testing at WSTF using distributed feedback (DFB) laser diodes. A companion effort recently demonstrated that like performance for hydrogen chloride (HCL) can be provided using a similar architecture. Two recent developments have enabled a multi-gas optical acid gas monitor with increased performance. 1) Demonstration of sub-parts-per-million (ppm) sensitivity for HCL at $1742 \mathrm{~nm}$ allows implementation in a common sample cell with the HF sensor operating at $1312 \mathrm{~nm}$ and using the same electronics. 2) The emergence of vertical cavity surface emitting laser (VCSEL) diodes at both wavelengths eliminates the need for fiber-coupled telecom devices which draw much more power and reduce portability. The new prototype device employed in the present WSTF testing combines VCSEL-based, real-time, high-performance concentration measurements with rapid sampling for both HF and HCL simultaneously. Little surface interaction is suffered as the gas samples need only traverse a few $\mathrm{mm}$ aperture to enter the optical cell and are directed across the aperture by a simple fan. A second Phase III-developed HF sensor, utilizing a fiber coupled DFB laser diode at $1312 \mathrm{~nm}$, was also employed in the present testing. HF measurement precision is better than $0.1 \mathrm{ppm}$ and HCL is better than $0.2 \mathrm{ppm}$.

A VCSEL-WMS sensor for CO utilizing a simple optical multipass cell was designed and built on a Phase II SBIR project (CO multipass analyzer, COMA). The delivered sensor version operates with a netbook computer (Mini 9, Dell). Although the sensor has already been operated with Field-Programmable Gate Array (FPGA) electronics during the Phase II project, the netbook based version is more flexible and allows easy change of sensor parameters. The netbook based version is more suited for WSTF testing due to its adaptability in the field. The sensor dimensions are $17.8 \mathrm{~cm}$ x $12.7 \mathrm{~cm}$ x $8.1 \mathrm{~cm}$ (not including the netbook). An FPGA based (stand-alone) CO sensor has similar dimensions. Note that the aim of the electronics development is to operate the CO sensor as an additional channel of an emerging Vista Photonics combined combustion products monitor (CPM). The sensor cell is designed for compactness and ruggedness. It has no moving parts; all components are solidly mounted. Cell dimensions are about business card size. In the developed sensor cell the laser is solidly attached to the cell at an angle. This angle is precisely machined into the cell. It determines the number of passes through the cell. Eight passes are realized in this cell leading to an absorption path-length of $63.6 \mathrm{~cm}$. Measurements at WSTF were performed with a low-power, non-temperature stabilized sensor. Free-space single mode $2330 \mathrm{~nm}$ VCSELs are utilized in the COMA architecture. The VCSELs typically deliver about $0.3 \mathrm{~mW}$ of output power in single mode operation and are tunable from about $2333 \mathrm{~nm}$ to $2341 \mathrm{~nm}$. CO measurement precision is about $0.5 \mathrm{ppm}$.

\section{B. Fixed and Portable Smart Space Fire Detection System (SSFD)}

Fixed and portable version of a Smart Space Fire Detection System (SSFD) developed by Makel Engineering, Inc. and NASA GRC were tested. Intial versions of these systems were tested in 2011 [5]. The SSFDS includes the core electronics, interfaces, microprocessor, and overall hardware architecture from the "Lick and Stick" technology developed for space flight leak detection applications and a fire detection system developed for aeronautics [5-6] . 
The current generation of the SSFD sensor system provides the capability to detect $\mathrm{CO}, \mathrm{CO}_{2}, \mathrm{O}_{2}, \mathrm{H}_{2}$, and hydrocarbons while tracking temperature, pressure, and humidity. The individual solid state sensors are integrated into a single package that is approximately $17.8 \mathrm{~cm}$ wide $\times 10.2 \mathrm{~cm}$ long x $4.6 \mathrm{~cm}$ tall, excluding the external cable, with weight and power consumption near a $1 \mathrm{~kg}$ and $6 \mathrm{~W}$ respectively. There is an electrical connector for power and RS485 communication, but the system can be configured for wireless capability. The portable version of the device includes a touch screen LCD, sampling pump, and rechargeable battery. For the fixed system the sensor elements are exposed to the external environment by diffusion through stainless steel filters standardly used in combustion product monitoring, but are sealed internally from the rest of the electronics and enclosure. For the portable SSFD, a sample pump inside the unit pulls air to the enabling the system to used as a sniffer. The overall design of the unit enables the device to incorporate new sensor types and improved sensors for individual species with minimal rework of the unit. The modular electronics also enables upgrade and improvement to the hardware. The MEMS chemical sensor technology used in the both systms consists three different types of MEMS chemical sensor platforms resistors, solid state electrochemical cells, and Schottky diodes. Each sensor type or platform provides very different types of information on the environment and is meant to have limited cross-sensitivity (i.e., be orthogonal in its response). Integration of the information from these orthogonal sensors can provide increased whole-field information on the environment. The approach is to give quantitative readings of the species of interest. The current generation of the systems tested included specific improvements to $\mathrm{CO}$ and $\mathrm{CO}_{2}$ sensor sensitivity and stability. In addition, refined real-time algorithms for improving individual sensor selectivity were implemented. Thus, this testing employed the same core sensor technology, but integrated with different hardware platforms and implemented at different locations in the test environment. The data presented in this paper will concentrate on the results provided by two types of $\mathrm{CO}$ sensors in both a fixed position unit and a portable unit. One sensor is intended for low concentration measurements (Fixed-L and Portable-L) and is intended to also have use in environmental monitoring. The second type of $\mathrm{CO}$ sensor is intended have a broad range of detection capabilities extending into higher levels of $\mathrm{CO}$ concentration that may be present in some fire conditions (Fixed-H and Portable-H). Data from the other sensor technologies was also recorded and is available for future analysis and crosscorrelation.

\section{Compound Specific Analyzer-Combustion Products (CSA-CP), Draeger X-am 5600, Drager Pac III}

Several commercial multi-gas monitors were used in the test, including the Compound Specific AnalyzerCombustion Products (CSA-CP) from Industrial Scientific which is identical to that used on the International Space Station, and an X-am 5600 unit from Draeger. Both measure $\mathrm{O}_{2}, \mathrm{CO}$, and $\mathrm{HCN}$ electrochemically. Additionally, the CSA-CP measures $\mathrm{HCl}$ electrochemically and the $\mathrm{X}$-am 5600 measures $\mathrm{CO}_{2}$ by infrared detector. Both units were calibrated at Johnson Space Center in Houston prior to the test and checked at WSTF before and after the testing. The units were located front and center inside the chamber (see Figure 1) to be able to see the display and record the maximum concentrations during each test. Data were also automatically logged and downloaded after all testing was completed. The Draeger PacIIIs are single gas electrochemical monitors equipped with sensors for CO, $\mathrm{HCN}$, and HF/HCL. These three units were also located near the front ports. Prior to testing these monitors where calibrated using commercial certified gas standards.

\section{Aerosol Thermal Precipitator}

A thermal precipitator was designed at Glenn Research Center to collect smoke aerosol particles for microscopic analysis. The design takes advantage of the thermophoretic force on a particle in a large temperature gradient created by opposing thermoelectric coolers and kapton heaters. The particles are driven to the cold side of the gradient, which in this device is set of SEM stubs prepared with a section of carbon tape and TEM grids to facilitate a variety of analyses. Information on particle morphology, size, chemical composition and agglomerate structure obtained from these tests supplements aerosol concentration data collected.

\section{E. Tapered Element Oscillating Microbalance (TEOM) Personal Dust Monitor (PDM)}

The TEOM is a direct-reading gravimetric aerosol instrument manufactured by Thermo Fisher Scientific that measures aerosol mass deposited on a filter. The filter is mounted on a hollow tapered glass stalk through which air is drawn and which vibrates at a frequency proportional to the mass on the filter. The system electronics monitor the frequency changes, and changes in mass on the order of micrograms are computed and recorded every 5 seconds. Aerosol mass concentration can be derived from the change in mass on the filter and the known volumetric flow rate of air through the filter. The PDM is a wearable respirable dust sampling version of the TEOM for use in mining and other hazardous occupations. 


\section{F. DustTrak DRX Monitor and DustTrak II}

Aerosol photometers measure mass concentration by measuring the combined laser light scattered from many particles at once. Both DustTrak TM monitors (TSI Inc.) are the same except the DRX combines ensemble scattering with single particle detection to provide real-time size-segregated mass fraction concentrations up to 150 $\mathrm{mg} / \mathrm{m}^{3}$. In this testing, aerosols below $1 \mu \mathrm{m}$ in diameter are the predominant sizes however it is of interest in fire characterization to determine which fuels generate particles above this threshold. Optical aerosol instruments give a material-dependent response, with particle refractive index dictating the amount of light scattered. This instrument is factory calibrated with Arizona Road Dust for the wider market of occupational hygiene applications. A custom calibration for smoke was performed using a polydisperse mineral oil aerosol that resembles the size distribution of smoke.

\section{G. P-Trak 8525}

The P-Trak ${ }^{\mathrm{TM}}$ (TSI Inc.) is a condensation particle counter that measures aerosol number concentration. This device operates by passing the aerosol-laden particle stream through a region saturated with isopropanol vapor and then into a cooler region where the vapor condenses onto the particles increasing their diameter such that they can be readily counted by a light scattering device. This instrument is designed for the occupational hygiene market and operates over a range of 0 to $10^{5}$ particles $/ \mathrm{cm}^{3}$ and $20 \mathrm{~nm}$ to $1 \mu \mathrm{m}$ diameter. Dilution is required, since the smoke concentration is higher than the upper range limit.

\section{H. GC/MS}

A Hewlett-Packard ${ }^{\circledR 1}$ 5890A Gas Chromatograph with a 5970 Series Mass Selective Detector was assembled to perform analyses of combustion products. The Gas Chromatography with Mass Spectral Detection (GC/MS) instrument was equipped with a $30-\mathrm{m}$ x $0.53-\mathrm{mm}$ ID x $5-\mu \mathrm{m}$ phase 100 -percent dimethyl polysiloxane capillary column, a VICI ${ }^{\circledR 2}$ direct injecting $10-\mathrm{mL}$ sampling loop, and a 6-port valve. To obtain a sample, a 12 -ft heated transfer line, transfer line isolation valve, vacuum pump, and vacuum pump isolation valve were used to move the gas sample from the mask to the sampling loop. The inlet system is configured so that the vacuum pump evacuates the valve, loop, and heated transfer line to the transfer line isolation valve. The vacuum pump isolation valve is then closed and the heated transfer line isolation valve opened to pull in the gas sample to be analyzed. After the gas sample is pulled into the loop, the pressure is measured, the 6-port valve switched, and the gas sample injected onto the column.

\section{Ion Chromatography}

The wet-trap samples were acquired by pulling an air sample from the chamber over a sorbent wetted with deionized water at a measured air flow rate for a specific time. This sorbent was then desorbed into $10 \mathrm{~mL}$ of IC eluent, filtered then run on the ion chromatograph (IC). Chamber concentration of acid gas was calculated by flow rate, time, volume of water in the trap and concentration of the corresponding anion determined by the IC.

\section{Results and Discussion}

With the exception of the GC/MS data, all of the results from the two testing campaigns are tabulated in the appendices. While all individual chemical parameters could be plotted and commented on, only select data are analyzed, plotted and discussed as examples or highlights for brevity. Photographs of the residual ash after testing are shown in Figure 4 and masses are given in Appendix E.

The goal of the testing, along with proving instrument performance, is to consider spacecraft fire characteristics, including gas and aerosol signatures. Many topics concerning the data merit their own dedicated study, however, some of the chemical and aerosol results are discussed here in light of ongoing WSTF testing and the sensors under development.

\section{A. Particle Microscopy}

As part of the particle characterization of smoke aerosols generated during two White Sands testing regimens, samples were collected via a thermal precipitator. The thermal gradient allows particles to collect on scanning electron microscopy (SEM) stubs and transmission electron microscopy (TEM) grids. A strip of conductive carbon

${ }^{1}$ Hewlett-Packard ${ }^{\circledR}$ is a registered trademark of Hewlett-Packard Development Company, Houston, TX.

${ }^{2} \mathrm{VICI}^{\circledR}$ is a registered trademark of Valco Instruments Company, Inc., Houston, TX. 
film was placed onto the surface of the SEM stub to allow for viewing of the particles on both the aluminum stub substrate as well as a neutral carbon background. TEM grids with a) contiguous carbon film as well as a b) holey carbon film were placed at the edge of the carbon film to allow sample collection for higher magnification examination. Observations about aerosol particle size and morphology are made with a Hitachi SEM and Philips TEM. Elemental information is gained by use of an EDAX energy dispersive $\mathrm{x}$-ray analyzer (EDS) instrument on the SEM. The images shown here are typical of those generated by the heated samples.
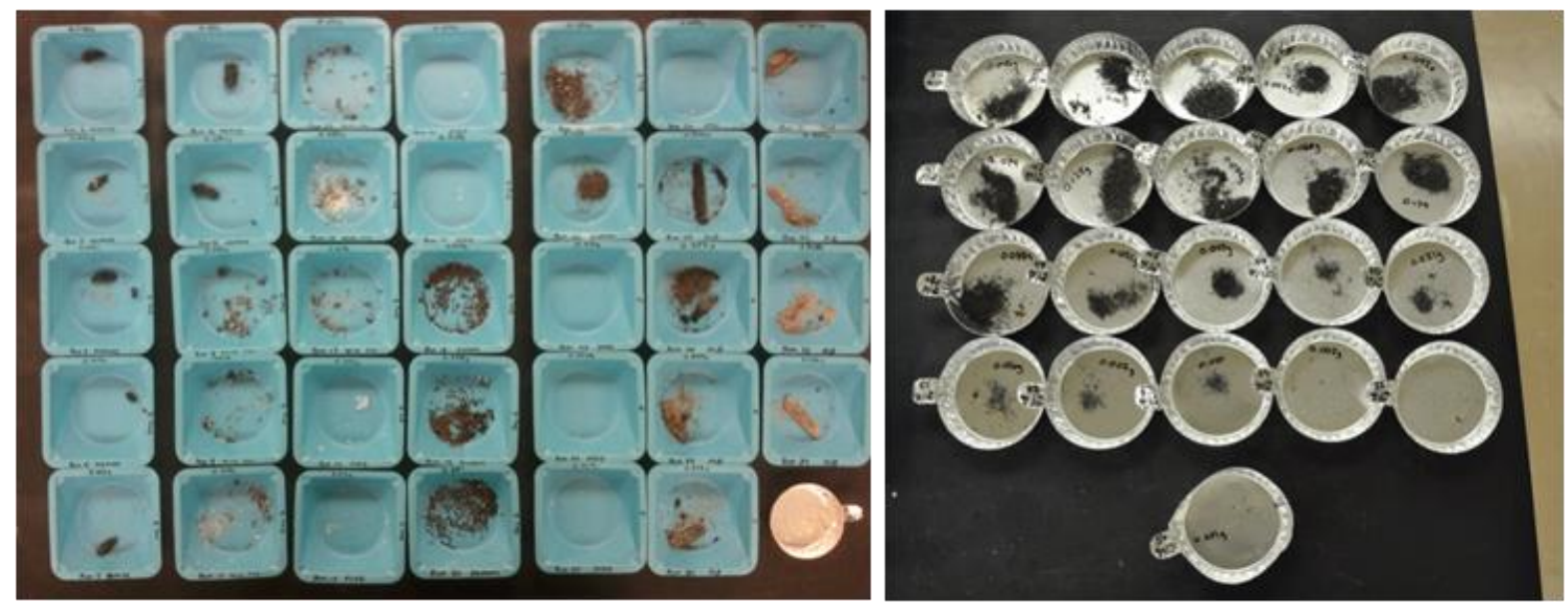

Figure 4. September sample ash after burning, arranged in chronological order of tests.

A $100 \%$ Teflon sample burned at $640{ }^{\circ} \mathrm{C}$ during February testing is shown in Figure 5. Teflon particles are generally spherical. Other areas on the $640{ }^{\circ} \mathrm{C}$ sample SEM stub (not pictured here) show evidence of acid pitting (potentially from HF), as well as the precipitated particles. The image on the left is a SEM image of precipitated particles and the center image is an elemental map showing fluorine $(\mathrm{F})$ within the particles. It is interesting to note that the fluorine is still concentrated in the aerosol particles which indicates that the material did not decompose significantly during the test. Another indication that the Teflon is still intact is shown in the TEM image on the right where the Teflon particle exhibits a crystalline interior with an amorphous coating.

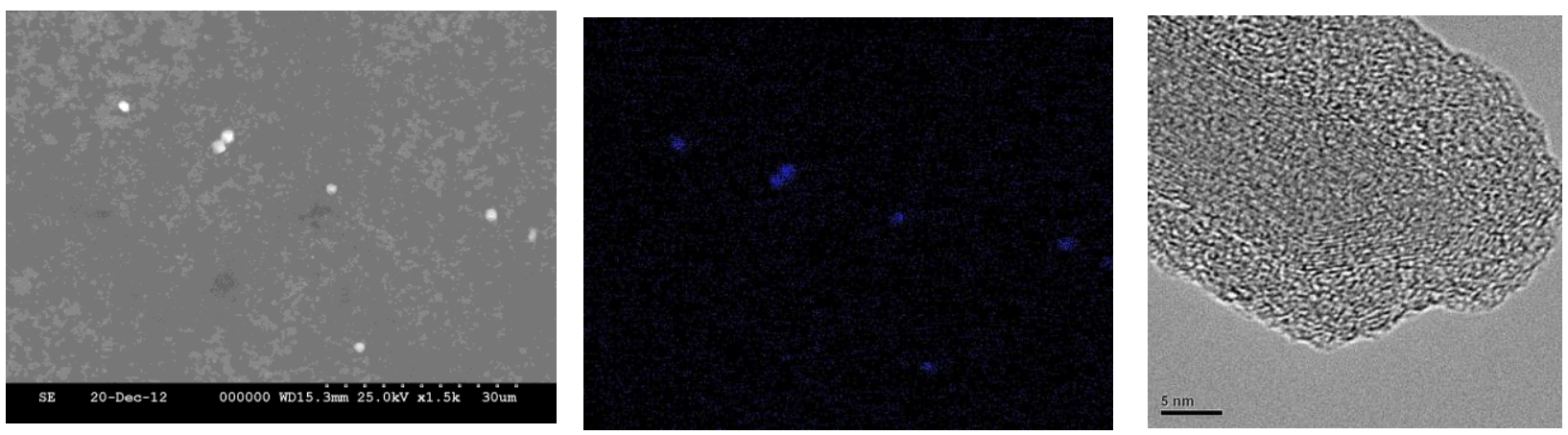

Figure 5. Teflon sample at $640^{\circ} \mathrm{C}$ on SEM stub with map showing concentration of fluorine (center) and HRTEM image (right).

Figure 6 illustrates particles from the September tests. This is a sample of a circuit board at $640^{\circ} \mathrm{C}$. Circuit boards exhibit significant amounts of particle deposition. Elements detected within these particles include oxygen, copper, iron, silicon, and fluorine; a representative EDS spectra from this sample is shown on the right. The gold in the EDS spectra is from a coating sputtered onto the stub to prevent charging. 

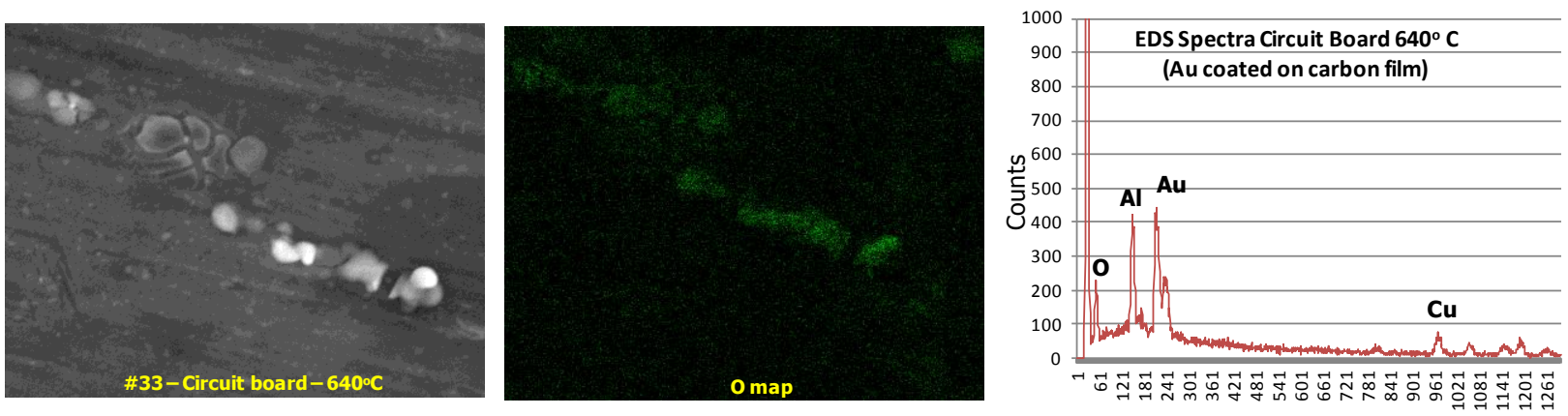

Figure 6. Circuit board sample at $640^{\circ} \mathrm{C}$ with map showing concentration of oxygen (center) and a typical EDS spectra (right).

Nomex particles were mostly spherical. EDS results indicate that Nomex aerosol particles contained bismuth, which is a heavy metal additive that increases flame retardancy and inhibits smoke generation. Particles captured from other sample materials were all mostly spherical with the exception of the Kapton, which exhibited string-like agglomerate structures. Figure 7 shows representative images of the wire insulation, Kapton and Teflon, all at $640^{\circ}$ C. The thermal precipitator was not designed to capture particles for the purpose of generating a particle size distribution by microscopy. The design intent was to give insight into particle morphology and smoke repeatability, and there may be some size fractions that were not captured at all due to the limitations of the thermophoretic sampling process, fixed flow rate and other design parameters.
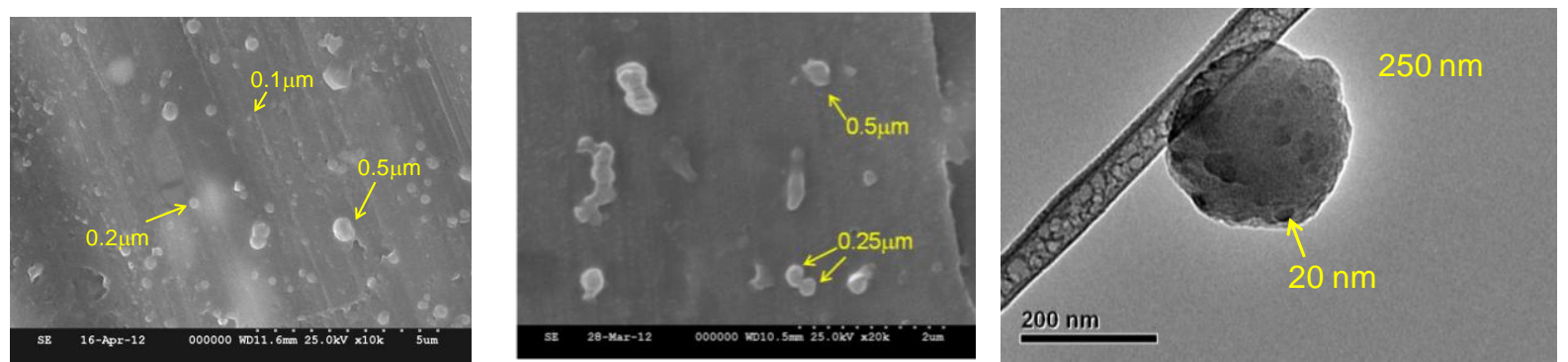

Figure 7. Wire insulation particles at $640^{\circ} \mathrm{C}$ are nearly spherical (left), some Kapton particles at $640^{\circ} \mathrm{C}$ exhibit chain-like agglomerate structure (center), a $640^{\circ} \mathrm{C}$ Teflon particle which is a compact agglomerate made up of nanoparticle primaries. The rod to which the particle adhered is the carbon film of the TEM grid.

\section{B. Chemical Combustion Products: Select Results and Trends}

A significant amount of data across multiple chemical sensor systems was collected during this testing. The Appendices briefly summarize the large amounts of raw data associated with various test runs. In general, there was notable consistency amongst the various sensor outputs although some variation was noted. Analysis of this data, evaluation of sensor system performance, and reasons for potential variations in sensor response is beyond the scope of this paper, and an appropriate subject for a separate paper. The purpose of this section is to give general trends and summarize some of the highlights of the data observed this testing.

Much of the chemical data (peak concentrations from all sensors for each run) from the September 2012 test $\left(640^{\circ} \mathrm{C}\right.$ without ignition) is reduced and displayed in Fig 8 as averages and ranges, although the PFPI wire insulation and Standard Mix data are from the Feb test. Figure 8 serves as a quick comparison chart and reference for gas production vs. material and is helpful in designing combustion experiments and sensor evaluations in a "relevant environment". The CO concentration range for Kapton was the widest for a single material, and PTFE the smallest. CO yield for PTFE was also smallest (9 ppm average). Mixtures (PTFE/Kapton indicated as mass percentages) gave interesting results. A small amount of Kapton added to PTFE dramatically increased CO and vice versa. Yield for M22759 wire insulation is similar in CO production to 90/10 PTFE/Kapton, whereas the PFPI wire insulation approaches that of 75/25 PTFE/Kapton. As expected the PTFE and PTFE containing fuels produce the 
highest HF concentrations whereas materials like Nomex, containing no fluorine naturally do not produce HF. The PCB and Standard Mix produce little HF. The 2 different types of wire insulation gave similar average HF production with differing ranges. A small amount of Kapton in Teflon mixture appears to boost production of HF. Future work should include a study of the role of proton donor in HF production. As expected, Kapton is best producer of HCN and PTFE least (zero). Interestingly, a small amount of PTFE in Kapton seems to boost HCN production. The $4 \mathrm{ppm}$ average HCN from M22759 wire insulation reflects the tape wrap style construction-a thin layer of polyimide between 2 layers of PTFE. PFPI wire insulation produces little HCN, although the backbone is polyimide. That observation along with the high HF signature indicates that "partially fluorinated" is actually a large degree of fluorination.

The September test was the first to detect HCL unequivocally from PVC and PVC-containing mixtures via TDLS. Presence of significant acid gases were confirmed via the wet trap ion chromatography results (see Appendix B \& D). As an example, Fig 9 shows that acid gases persist in the chamber longer than expected - there is a spike in production then an initial rapid decay, in which $\mathrm{HF} / \mathrm{HCl}$ are reacting with surfaces in the chamber, then a slow decay, with these toxic species persisting for 10's of minutes. It appears the surfaces become less accommodating for the acid gases during prolonged exposure. Note that the HF concentration never returns to zero between runs after the chamber has been exposed a few times. Run 13 (Fig 9 right) was allowed to run for an extended period, and results show HF still present after more than two hours. An exponential model would predict nearly complete decay of HF within about 20 minutes based on the initial, rapid, decay. Nonetheless, after 20 minutes the HF concentration is about four times higher than predicted by an exponential fit. This has implications for fire response on spacecraft and other closed inhabited environments and for combustion product monitor development.

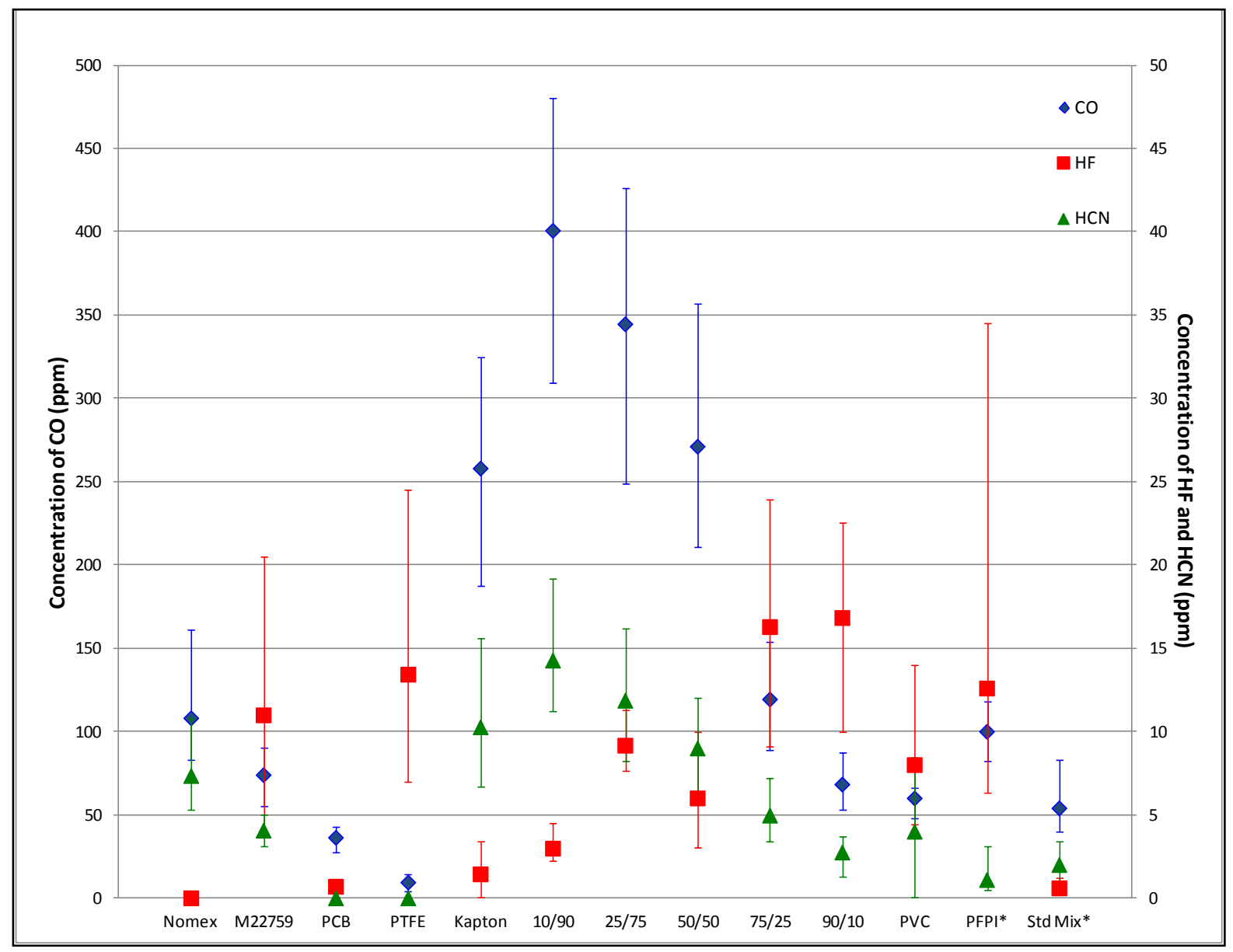

Figure 8. Range and Average of Maximum Concentration of Gas Products vs. Fuel Material at $640^{\circ} \mathrm{C}$.

11

American Institute of Aeronautics and Astronautics 

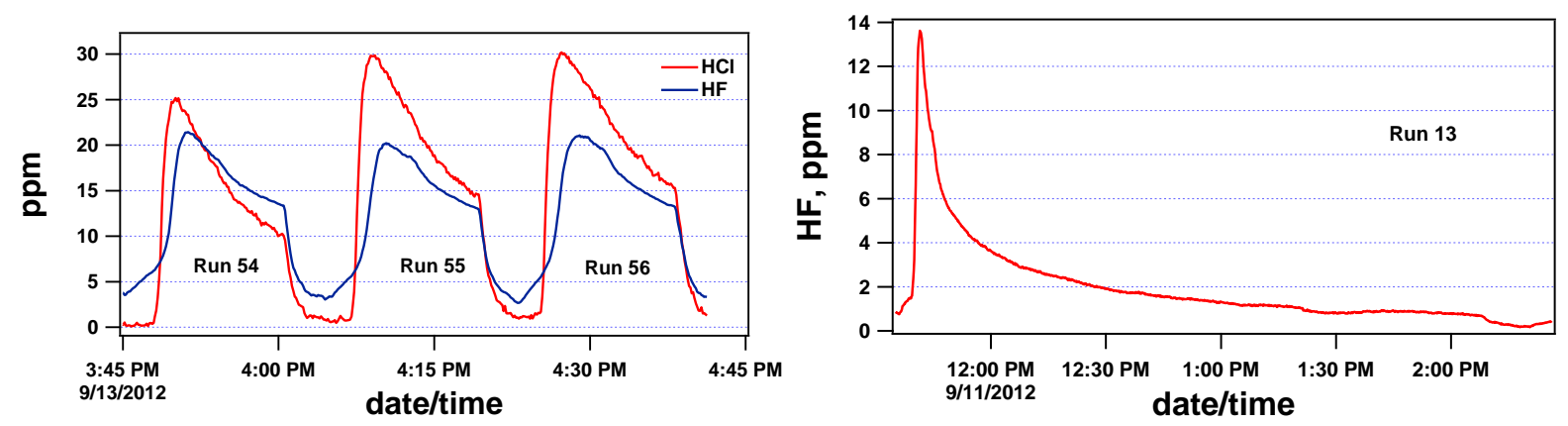

Figure 9. Production and persistence of HF and HCL from PTFE/PVC burns (Runs 54-56, Left), each with a short decay before venting the chamber, and HF from the burn of M22759 wire insulation (Run 13, Right) which was intentionally left to decay for approximately 3 hours.

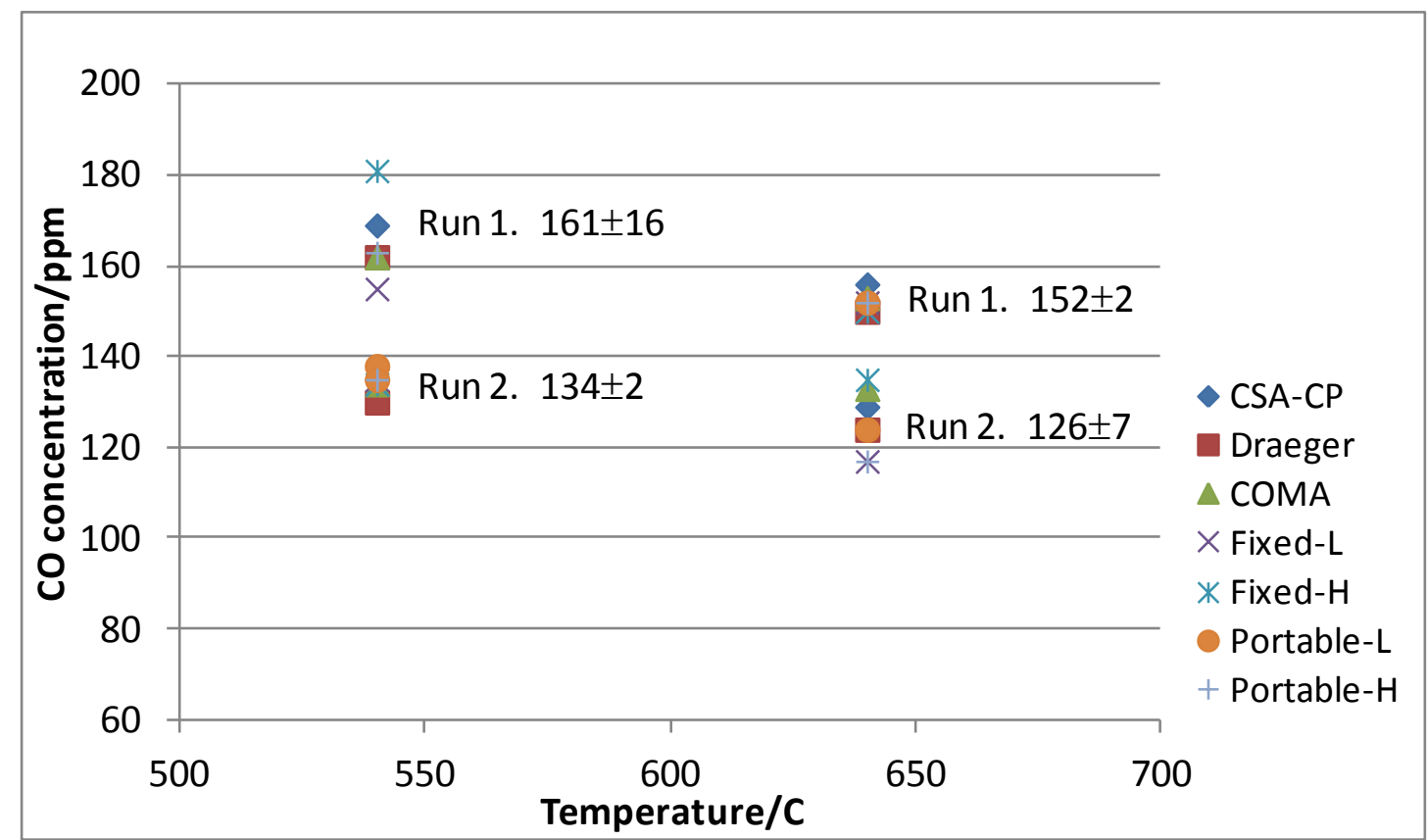

Figure 10. Comparison of CO sensor performance for Kapton at 2 burn temperatures (February/March).

Different sensor technologies were compared in the tests with standard commercial units. Figure 10 illustrates one such analysis-- the maximum CO values from all sensors in Kapton runs during the February/March test, which showed remarkable precision with all sensors reporting CO within $10 \%$ of the mean for a given run. Results varied between runs, but that was a function of other factors--studied in a little more depth in the September test. The Sept 2012 test sequence was our most recent and most well controlled, so it is the best data for which to discuss run-torun variability (reproducibility) for the current practice. The September data in Appendices C and D includes calculated average and standard deviation. Based on the $\mathrm{CO}$ results, the run-to-run reproducibility within a given material, with the exception of PTFE, ranged from 12.5 to $18 \%$ relative standard deviation (RSD). The M22759 wire insulation had the lowest RSD for $\mathrm{CO}$ at $12.5 \%$, indicating best reproducibility as measured by all the $\mathrm{CO}$ sensors. The RSD for PTFE was about double (29\%), but that is likely from the fact that the CO yield is low for PTFE $(9+/-3 \mathrm{ppm})$. The run-to-run RSD for HCN from Nomex was about $20 \%$ and that for M22759 wire insulation was $15.3 \%$, which indicates decent reproducibility in terms of $\mathrm{HCN}$, despite the lower yields. Because 
the acid gas yield was generally also much less than $\mathrm{CO}$ (except for PTFE) and more reactive than $\mathrm{CO}$ and $\mathrm{HCN}$, the RSDs tend to be higher for $\mathrm{HF}$ and $\mathrm{HCl}$, thus less useful for assessing run-to-run variation.

\section{1) Fuel Preparation Effects}

Testing in February/March involved mostly pelletized fuel. This was the approach taken for the early fire cartridge testing process in 2010 and had persisted for subsequent campaigns. The standard mix had variation in the textures of the constituent materials that the pellet provided a consistent starting configuration. Some materials retained the pellet shape throughout the burn whereas other materials collapsed into granules, providing more available surface area. When the pellet remains intact, the thermal decomposition mechanism may be altered by the presence of a char front that progresses into the pellet over the duration of the test. Combustion products generated at the char front must traverse the surrounding ash in order to be liberated. This process was never rigorously investigated, however, in order to remove this variability between fuel materials, the second round of testing was performed without the pellet press. Thus all the fuels had a larger surface area available for thermal decomposition.

\section{Less HF from Pelletized Fuel versus Powder}

The pelletized blends of PTFE and Kapton produced significantly lower levels of HF than the loose mixtures as determined by the identical HF optical sensor placed in the same relative proximity to the combustion source. While the two rounds of testing occurred about 6 months apart for the pelletized samples and the loose samples, relatively good agreement was obtained for wire insulation samples under the same test conditions (e.g. $640^{\circ} \mathrm{C}$ ). Figure 11 presents the wire insulation samples average HF production over multiple replicates as a horizontal line. Although different types of wire, note the good agreement from the two rounds of testing for the wire insulation regardless of whether the sample was pelletized or loose. It stands to reason that the wire insulation is already well mixed due to the nature of its construction and that pelletized or loose grouping of the insulation does not significantly impact surface interaction effects which are those likely responsible for promoting HF production. Importantly, there is a significant difference in HF promotion based on whether the blended samples are pelletized or loose. Indeed, the pelletized blends, regardless of mixture fraction, never produce as much HF as the pelletized wire insulation. In contrast, the higher PTFE fractions in the loose mix produce more HF than that produced by the loose wire insulation. This is strong evidence for the importance of surface and localized gas phase interactions between the PTFE and Kapton materials in producing HF. The wire insulation produces high levels of HF in both cases and provides large surface interaction between the two materials. Likewise, the loose mixtures may produce more HF because of the blurring of inside versus outside interactions produced by the pellet arrangement. The loose material also likely heats up more uniformly over a greater surface area than the pelletized material. For larger PTFE fractions the wet trap results (Fig 11) are significantly higher, perhaps indicating there are other fluorinated products that hydrolyze and yield additional fluoride in the wet trap.

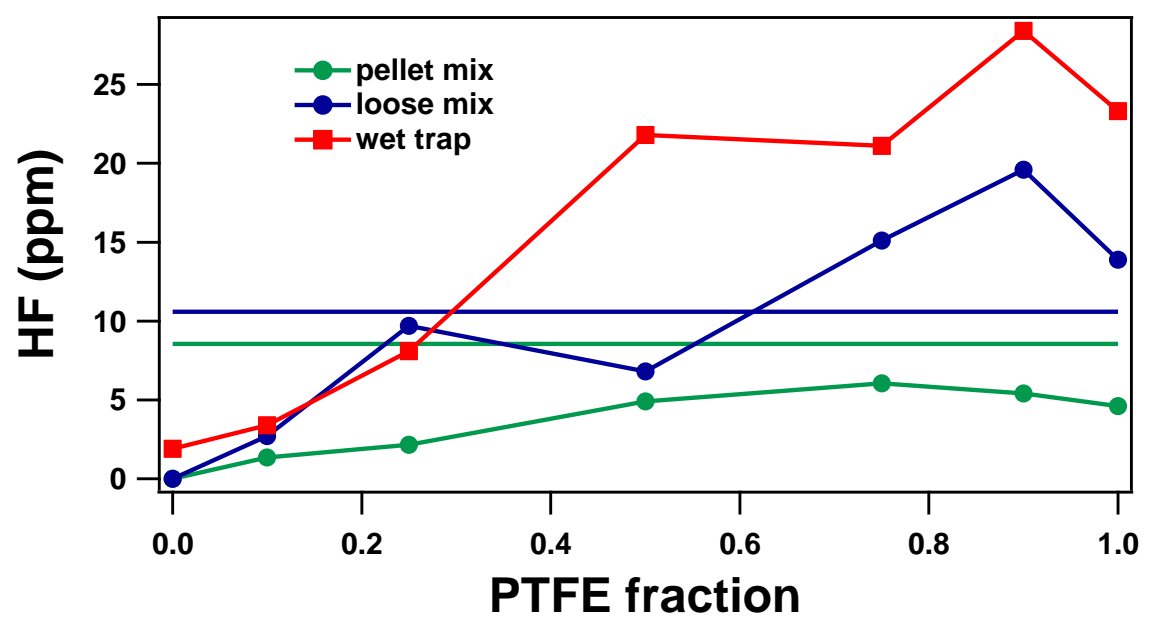

Figure 11. Concentration of HF as a function of PTFE fraction in sample material mixture, compared with the horizontal lines which depict wire insulation samples' average HF production over multiple replicates. 


\section{Effect of Fuel Preparation on Smoke Aerosol}

It was observed that the aerosol mass concentration was approximately equal for a $100 \%$ PTFE pellet in the February/March testing and the loose ground PTFE test in September. This can be attributed to the nature of ground PTFE, which does not hold its pellet shape very well in spite of 10,000 psi of the pellet press. Thus the pellet process was never effective on that material. September testing showed the effect of the commercial $100 \mu \mathrm{m}$ PTFE powder which makes $1 / 3$ more aerosol mass concentration than the ground PTFE. The ground PTFE had granules that were much larger than $100 \mu \mathrm{m}$, as can be seen in the unburned fuel samples in Figure 3. The most significant effect of fuel preparation on aerosol output was with Kapton, where it was seen that the granulated Kapton produced five times more aerosol mass concentration than the Kapton film squares, which can be attributed to more surface area in granulated Kapton. The wire insulation was changed between the two test campaigns, and the average aerosol mass concentration in February/March was $0.013 \mathrm{~g} / \mathrm{m}^{3}$ but the September test version of insulation averaged $0.050 \mathrm{~g} / \mathrm{m}^{3}$.

\section{Excessive Production of HF from Wire Insulation Compared to PTFE/Kapton blends}

Figure 12 shows the production of HF and HCN from a variety of PTFE and Kapton blends (two-component mixture only) as a function of blend fraction in the "loose mix". Both optical PAS and electrochemical CSA-CP sensors are in qualitative agreement on the production of $\mathrm{HCN}$ as a function of Kapton fraction. There is an interesting and unexpected drop in measured HCN levels with pure Kapton ( 0.0 PTFE fraction) indicated by both sensors. The HF signal determined optically shows a like drop off in pure PTFE (1.0 fraction) relative to blends with even a small amount of Kapton (0.9 PTFE). However, that is likely caused by the lack of available hydrogen in pure PTFE resulting in a reduction in HF production relative to other, undetermined, fluorine containing combustion products. There is also an anomalous drop in HF production at 0.5 PTFE fraction which showed up in the two

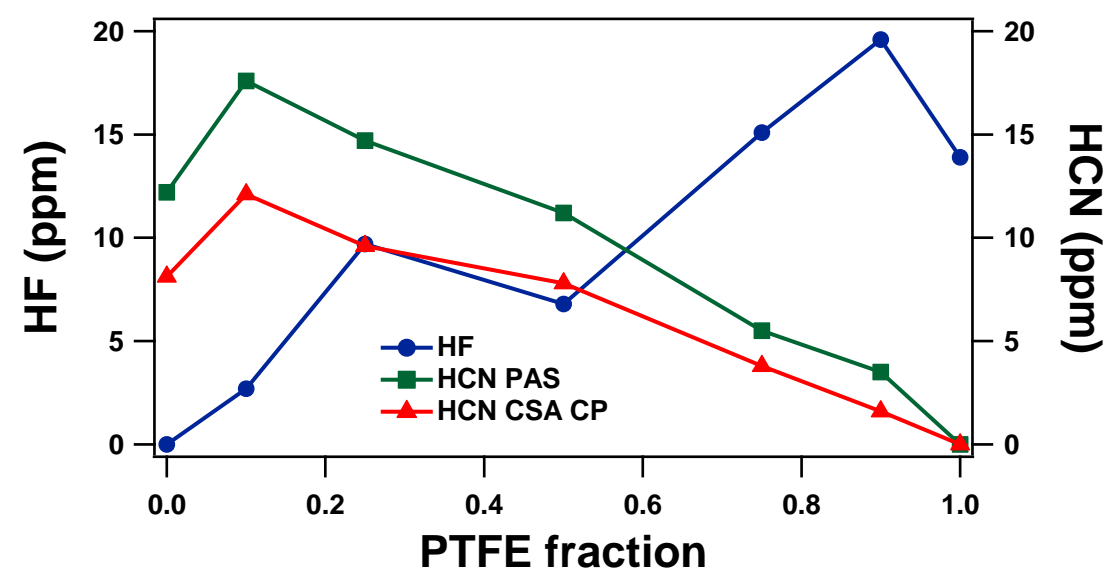

Figure 12. Production of HF and HCN as a function of PTFE fraction in sample material mixture.

separate optical sensor HF measurements. A possible explanation is that the 0.5 PTFE fraction measurements were made at the beginning of the testing regimen before the test chamber surfaces could have become passivated towards reactive gases. Nonetheless, the data show a fairly monotonic increase in HF with PTFE fraction and monotonic increase in $\mathrm{HCN}$ with Kapton fraction.

\section{Sample Mass Loss}

The residue from burned samples was weighed and recorded. A complete mass balance of the pyrolysis process was not attempted, however, the general trends in mass loss can give insight into the fire signature of various materials. The aerosol mass concentration in the exposure chamber was nearly constant throughout the heating cycle after the initial temperature ramp. Thus, an approximate total aerosol mass could be calculated from the mass concentration recorded with the known volume of the exposure chamber. Refer to Appendices $\mathrm{E}$ and $\mathrm{F}$ for the estimated mass of particles and ash mass from each test, and Figure 4 for photographs of the sample remains.

Ash mass was significantly affected by pelletization for Kapton. Loose samples had an average ash mass that was 15 to 30 times as large as the pelletized Kapton. Circuit board ash mass was larger than most other materials since the substrate FR-4 is designed to char, not combust. The combined ash mass and estimated aerosol mass 
account for more than $70 \%$ of the initial sample weight, which is unusual compared to most materials tested. Nomex samples had nearly equal ash mass and estimated aerosol mass. Teflon samples had the smallest ash mass remaining after testing, with the average remaining mass only $16 \%$ of the original mass $(0.5 \mathrm{~g}$ sample).
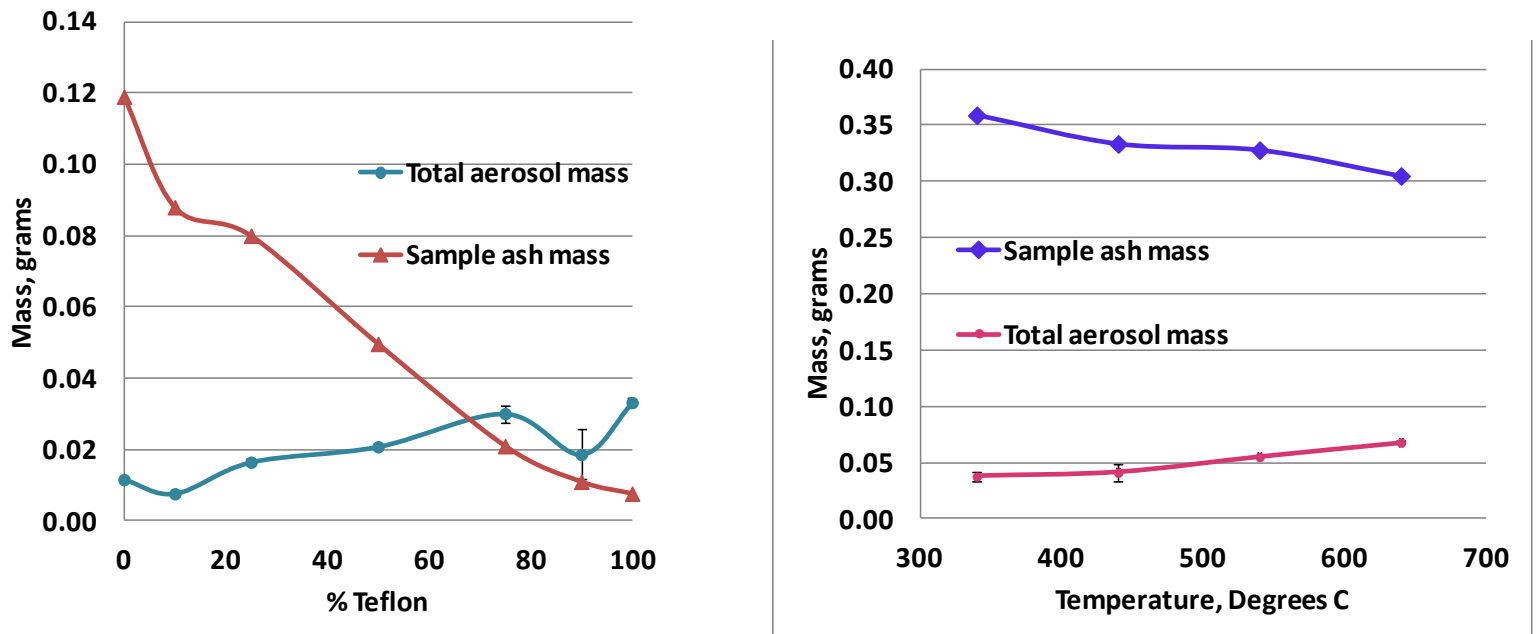

Figure 13. Mass accounting plots for Teflon/Kapton mixture tests (left) and granulated circuit card tests as a function of temperature for September tests. Error bars on aerosol mass represent one standard deviation.

The Teflon aerosol had a higher aerosol number concentration than most materials, but is made up of much smaller particles which filled the TEOM filter, necessitating higher dilution ratios and frequent filter changes. The right plot in Figure 13, shows that the total aerosol mass increases as the percentage of Teflon in the Teflon/Kapton mixture increases, and the sample ash mass decreases as the percentage of Teflon increases. This is an expected trend which is also evident in the circuit card graph on the left in Figure 13. Aerosol mass increases with increasing temperature, and there is a corresponding decrease in sample ash mass with increasing temperature. The error bars on the total aerosol mass represent one standard deviation in the mass measurement, which demonstrates that the repeatability of the heating and smoke generation between replicates was very good.

\section{E. Improvements in Testing Methods and Results Between the Two Test Campaigns}

Improvements between the two test campaigns were predominantly in the repeatability of the measurements. This was mostly accomplished by eliminating the standard mix which was fraught with variability in the grinding process of the constituent materials, as well as in the pellet preparation process. For the September test campaign we focused primarily on $640^{\circ} \mathrm{C}$ furnace temperature to produce more replicates in one week's worth of testing. Future improvements will be made in the testing process, including ensuring that the acid gases have been sufficiently purged from the exposure chamber between runs. One method to control this is to incorporate a bakeout of the furnace between runs or more "air out" time between runs. Randomization in the order of the fuels may improve this as well, since the baseline HF concentration may be very small between different fuels instead of building up steadily when burning HF-producing samples all in succession. It has been observed that the first run of the day is often different, for example, $\mathrm{CO}$ is low for first fuel, first run of the day. $\mathrm{HCl}$ also did not return to zero between tests (this may take such a long time to accomplish that it would preclude the aggressive test schedule that is typically desired). A proposed solution is to subtract off a baseline value for subsequent tests. The electrochemical based devices are slow to rebaseline even in fresh air. We also noted that Nomex emits prolific chemical and particulate combustion products. Burning it first in the test campaign had consequences. Next time, Nomex will be burned on the last day.

Aerosols are notoriously difficult to generate consistently, particularly smoke aerosols. The February/March tests had very large ranges of aerosol mass concentration measurements, with the standard mix and $100 \%$ Teflon varying by a factor of 10 for the same temperature tests. There was a significant improvement in repeatability at the September testing where the focus was to improve this aspect of testing and to perform more replicates of the same tests. Over half of the standard deviations of the aerosol mass concentration measurements were less than $10 \%$ of the average values. The least repeatable materials in terms of mass concentration were the blend of circuit board 
and PVC, the 90\%-10\% Teflon-Kapton mix and the Kapton squares, which differed by a factor of two at the most. Aerosol number concentration varied by a factor of two to four for Teflon, the standard mix and $25 \%-75 \%$ TeflonKapton, at the February/March testing with the other materials having much better repeatability, but the best improvement was the September testing with only two fuels having a standard deviation which was greater than $10 \%$ of the average value. Teflon has proven to be the most difficult material in terms of aerosol measurement repeatability. The improvement in aerosol measurements can be attributed to several practices, including careful fuel preparation, improved timing of procedural steps (Table 3), using loose fuel rather than pellets and, in particular, elimination of the standard mix.

\section{Conclusion}

Ongoing testing of gas sensors at WSTF contributes to the development of fire detection systems and post-fire cleanup monitoring equipment. Characterization of the gas and aerosol fire signatures of these polymers has contributed to the goal of providing a consistent and well-understood fire challenge for sensor testing, as well as validating the requirements and informing the design for the eventual suite of instruments that will make up the next generation spacecraft fire detection system. One notable conclusion is the significant production and persistence of acid gases HF and HCL in the chamber from a relatively small amount of fuel $(0.5 \mathrm{~g})$. This result weighs heavily in the design of the next generation combustion product monitor which will eventually replace the aging CSA-CPs on International Space Station. A review of the volatile organic compounds results (GC/MS data) should yield interesting findings as well. Progress in testing and lessons learned have been noted for improving future testing campaigns. A future direction which merits its own study is an exclusive detailed study of HF production from fluoropolymer pyrolysis, looking specifically at the role of proton donors. Further, follow-up testing to investigate aspects of sensor system performance, both in simple gas mixtures and complex combustion environments, is warranted to better evaluate the capabilities of an individual sensor system. 


\section{Appendices}

Appendix A. Carbon Monoxide data from all instruments in the February/March Test (in ppm)

\begin{tabular}{|c|c|c|c|c|c|c|c|c|c|c|c|c|c|}
\hline \multirow{2}{*}{11} & \multirow{2}{*}{ 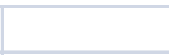 } & \multirow{2}{*}{ 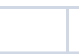 } & \multirow{2}{*}{ 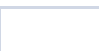 } & & & \multirow{2}{*}{ Vista } & \multirow{2}{*}{ Makel } & \multirow{2}{*}{ Makel } & \multirow{2}{*}{ Makel } & \multirow{2}{*}{\multicolumn{2}{|c|}{ Makel WSTF }} & & \\
\hline & & & & & & & & & & & & & \\
\hline & Fuel & $\mathrm{T} / \mathrm{C}$ & Ignite? & CSA-CP & Draeger & COMA & Fixed-L & Fixed-H & Port-L & Port-H & Paclll & Avg & Std Dev \\
\hline 1 & Std Mix & 540 & $\mathrm{~N}$ & 123 & 116 & 116 & 90 & 120 & 107 & 85 & -- & 108 & 15 \\
\hline 2 & Std Mix & 540 & Y & 47 & 46 & 44 & 53 & 50 & 55 & 49 & -- & 49 & 4 \\
\hline 4 & Std Mix & 540 & $\mathrm{~N}$ & 106 & 100 & 98 & 109 & 103 & 107 & 107 & 108 & 105 & 4 \\
\hline 5 & Std Mix & 540 & $Y$ & 71 & 70 & 64 & 72 & 75 & 67 & 73 & 73 & 71 & 4 \\
\hline 28 & Std Mix & 430 & $\mathrm{~N}$ & 41 & 40 & 39 & 39 & 48 & 38 & 39 & 41 & 41 & 3 \\
\hline 33 & Std Mix & 340 & $\mathrm{~N}$ & 86 & 82 & 85 & 76 & 88 & 69 & 74 & 24 & 80 & 7 \\
\hline 39 & Std Mix & 640 & $\mathrm{~N}$ & 55 & 52 & 53 & 46 & 83 & 57 & 42 & 40 & 54 & 13 \\
\hline 3 & PFPI Wire Ins & 540 & $\mathrm{~N}$ & 109 & 106 & 106 & 109 & 117 & 115 & 111 & 92 & 110 & 4 \\
\hline 6 & PFPI Wire Ins & 640 & $\mathrm{~N}$ & 95 & 94 & 98 & 100 & 88 & 91 & 96 & 99 & 95 & 4 \\
\hline 7 & PFPI Wire Ins & 540 & $\mathrm{~N}$ & 186 & 182 & 177 & 200 & 180 & 184 & 157 & 194 & 183 & 13 \\
\hline 21 & PFPI Wire Ins & 640 & $\mathrm{~N}$ & 98 & 96 & 102 & 118 & 107 & 82 & 108 & 112 & 103 & 11 \\
\hline 29 & PFPI Wire Ins & 640 & $\mathrm{~N}$ & 98 & 96 & 99 & 109 & 110 & 88 & 110 & 101 & 101 & 8 \\
\hline 31 & PFPI Wire Ins & 640 & $\mathrm{~N}$ & 94 & 90 & 95 & 102 & 114 & 106 & 134 & 95 & 99 & 8 \\
\hline 35 & PFPI Wire Ins & 540 & $\mathrm{~N}$ & 130 & 126 & 128 & 127 & 145 & 116 & 151 & 88 & 132 & 12 \\
\hline 8 & Circuit Brd & 540 & $\mathrm{~N}$ & 24 & 26 & 23 & 23 & 25 & 27 & 35 & 25 & 26 & 4 \\
\hline 10 & Circuit Brd & 640 & $\mathrm{~N}$ & 40 & 38 & 37 & 39 & 39 & 33 & 32 & 39 & 37 & 3 \\
\hline 23 & Circuit Brd & 640 & $\mathrm{~N}$ & 36 & 36 & 39 & 39 & 34 & 35 & 22 & 37 & 37 & 2 \\
\hline 27 & Circuit Brd & 340 & $\mathrm{~N}$ & 37 & 36 & 38 & 27 & 39 & 25 & $<20$ & 38 & 34 & 6 \\
\hline 34 & Circuit Brd & 430 & $\mathrm{~N}$ & 33 & 30 & 31 & 27 & $<20$ & 28 & 24 & 34 & 30 & 3 \\
\hline 9 & $100 \%$ TFE & 540 & $\mathrm{~N}$ & 5 & 0 & 5 & 6 & $<20$ & 8 & $<20$ & 5 & 5 & 3 \\
\hline 15 & $100 \%$ TFE & 640 & $\mathrm{~N}$ & 10 & 8 & 9 & 9 & $<20$ & 8 & $<20$ & 7 & 9 & 1 \\
\hline 20 & $100 \%$ PTFE & 540 & $\mathrm{~N}$ & 3 & 0 & nd & 4 & $<20$ & 5 & $<20$ & 0 & 3 & 2 \\
\hline 30 & $100 \%$ TFE & 640 & $\mathrm{~N}$ & 9 & 6 & 7 & 2 & $<20$ & 9 & $<20$ & 7 & 7 & 3 \\
\hline 42 & $100 \%$ TFE & 640 & $\mathrm{~N}$ & 8 & 6 & 6 & 5 & $<20$ & 2 & $<20$ & 12 & 6 & 3 \\
\hline 22 & $90 \% \mathrm{~T} / 10 \% \mathrm{~K}$ & 640 & $\mathrm{~N}$ & 19 & 20 & 20 & 16 & $<20$ & 18 & $<20$ & 19 & 19 & 2 \\
\hline 36 & $90 \% \mathrm{~T} / 10 \% \mathrm{~K}$ & 640 & $\mathrm{~N}$ & 34 & 34 & 37 & 30 & $<20$ & 32 & $<20$ & 24 & 32 & 4 \\
\hline 14 & 75\%T/25\%K & 540 & $\mathrm{~N}$ & 9 & 8 & 8 & 11 & $<20$ & 12 & $<20$ & 8 & 9 & 2 \\
\hline 19 & $75 \% \mathrm{~T} / 25 \% \mathrm{~K}$ & 640 & $\mathrm{~N}$ & 42 & 40 & 37 & 42 & 41 & 39 & 44 & 42 & 41 & 2 \\
\hline 32 & $75 \% \mathrm{~T} / 25 \% \mathrm{~K}$ & 640 & $\mathrm{~N}$ & 32 & 30 & 31 & 31 & 23 & 28 & 48 & 31 & 32 & 7 \\
\hline 12 & $50 \% \mathrm{~T} / 50 \% \mathrm{~K}$ & 540 & $\mathrm{~N}$ & 18 & 16 & 14 & 17 & $<20$ & 18 & $<20$ & 17 & 17 & 2 \\
\hline 17 & $50 \% \mathrm{~T} / 50 \% \mathrm{~K}$ & 640 & $\mathrm{~N}$ & 72 & 70 & 69 & 72 & 64 & 69 & 74 & 74 & 71 & 3 \\
\hline 25 & $50 \% \mathrm{~T} / 50 \% \mathrm{~K}$ & 640 & $\mathrm{~N}$ & 52 & 54 & 55 & 46 & 37 & 62 & 73 & 56 & 54 & 11 \\
\hline 13 & $25 \% \mathrm{~T} / 75 \% \mathrm{~K}$ & 540 & $\mathrm{~N}$ & 15 & 14 & 13 & 15 & $<20$ & 13 & $<20$ & 14 & 14 & 1 \\
\hline 18 & $25 \% \mathrm{~T} / 75 \% \mathrm{~K}$ & 640 & $\mathrm{~N}$ & 118 & 112 & 109 & 113 & 114 & 123 & 122 & 122 & 117 & 5 \\
\hline 38 & $25 \% \mathrm{~T} / 75 \% \mathrm{~K}$ & 640 & $\mathrm{~N}$ & 79 & 74 & 79 & 63 & 83 & 72 & 93 & 35 & 78 & 9 \\
\hline 43 & $25 \% \mathrm{~T} / 75 \% \mathrm{~K}$ & 540 & $\mathrm{~N}$ & 218 & 212 & 213 & 200 & 231 & 86 & 37 & 28 & 215 & 11 \\
\hline 24 & 10\%Т/90\%K & 640 & $\mathrm{~N}$ & 98 & 94 & 103 & 102 & 108 & 96 & 109 & 102 & 102 & 5 \\
\hline 37 & 10\%Т/90\%K & 640 & $\mathrm{~N}$ & 106 & 104 & 110 & 113 & 119 & 84 & 97 & 17 & 105 & 11 \\
\hline 11 & 100\%Kapton & 540 & $\mathrm{~N}$ & 135 & 130 & 134 & 135 & 134 & 138 & 135 & 135 & 135 & 2 \\
\hline 16 & 100\%Kapton & 640 & $\mathrm{~N}$ & 156 & 150 & 153 & 152 & 150 & 152 & 152 & 162 & 153 & 4 \\
\hline 26 & 100\%Kapton & 640 & $\mathrm{~N}$ & 129 & 124 & 133 & 117 & 135 & 124 & 117 & 132 & 126 & 7 \\
\hline 40 & $100 \%$ Kapton & 540 & $\mathrm{~N}$ & 18 & 16 & 14 & 38 & $<20$ & 7 & $<20$ & 109 & 19 & 12 \\
\hline 41 & 100\%Kapton & 540 & $\mathrm{~N}$ & 169 & 162 & 162 & 155 & 181 & 135 & 163 & 137 & 158 & 16 \\
\hline & Shading denotes a & aly & o run & nce err & nadvert & self) ign & on (omitted & from calculat & nns) & & & & \\
\hline$X X$ & Boxed values are & nite & 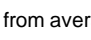 & 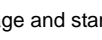 & ird devia & calculc & Conc & sions on s & sor $p$ & 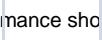 & ot & & \\
\hline
\end{tabular}

17

American Institute of Aeronautics and Astronautics 
Appendix B. HCN and acid gas data from all instruments in February/March Test (in ppm)

\begin{tabular}{|c|c|c|c|c|c|c|c|c|c|c|c|c|c|c|c|c|c|c|c|c|}
\hline \multirow[b]{2}{*}{ Run\# } & \multirow[b]{2}{*}{ Fuel } & \multirow[b]{2}{*}{$T / C$} & \multirow[b]{2}{*}{ Ignite? } & \multicolumn{6}{|c|}{$\mathrm{HCN}$} & \multicolumn{4}{|c|}{$\mathrm{HCL}$} & \multicolumn{5}{|c|}{ HF } & \multirow{2}{*}{$\frac{\text { HX }}{\text { PacllI }}$} & \multirow{2}{*}{$\frac{\mathbf{H B r}}{\text { Wet Trap }}$} \\
\hline & & & & Draeger & CSA-CP & PAS & PacllI & Avg & Std Dev & CSA-CP & Wet Trap & Avg & Std Dev & $\mathrm{HF}$ ii & $\mathrm{HF} \mathrm{iii}$ & Wet Trap & Avg & StdDev & & \\
\hline 1 & Std Mix & 540 & $\mathrm{~N}$ & 2.2 & 1.2 & 2.4 & -- & 2 & 0.6 & 16 & -- & -- & -- & 0.22 & 0 & -- & 0.1 & 0.2 & -- & -- \\
\hline 2 & Std Mix & 540 & $\mathrm{Y}$ & 0.7 & 0.2 & 0.9 & -- & 1 & 0.4 & 3.7 & -- & -- & -- & 2.1 & 4.3 & -- & 3.2 & 1.6 & -- & -- \\
\hline 4 & Std Mix & 540 & $\mathrm{~N}$ & 2.5 & 1.4 & 2.7 & 4 & 3 & 1 & 15.1 & 1.4 & -- & -- & 0.2 & 0 & 0.4 & 0.2 & 0.2 & 0 & 0 \\
\hline 5 & Std Mix & 540 & $Y$ & 1.0 & 0.5 & 1.3 & 1.5 & 1 & 0.4 & 1.2 & 1.5 & 1.4 & 0.2 & 1.3 & 1.3 & 3.3 & 2.0 & 1.2 & 5.2 & 0 \\
\hline 28 & Std Mix & 430 & $\mathrm{~N}$ & 1.4 & 0.3 & 0.8 & 4.3 & 2 & 2 & 9.5 & -- & -- & -- & 0.2 & 0.4 & -- & 0.3 & 0.1 & 0.9 & -- \\
\hline 33 & Std Mix & 340 & $\mathrm{~N}$ & 1.8 & 1.3 & 2.1 & 3 & 2 & 1 & 6.7 & 0.8 & & & 0 & 0 & 0.3 & 0.1 & 0.2 & 0 & 0 \\
\hline 39 & Std Mix & 640 & $\mathrm{~N}$ & 1.5 & 0.5 & 0.8 & 3.4 & 2 & 1 & 14.8 & 3.2 & & & 0.4 & 0.2 & 1.2 & 0.6 & 0.5 & 0.5 & 0.1 \\
\hline 3 & PFPI Wire Ins & 540 & $\mathrm{~N}$ & 2.7 & 1.8 & 3.2 & 6.7 & 4 & 2 & 5.4 & 2.9 & 4.2 & 1.8 & 16.5 & 21.7 & 33.8 & 24 & 8.9 & 0 & 0 \\
\hline 6 & PFPI Wire Ins & 640 & $\mathrm{~N}$ & 0.8 & 0.5 & 1 & 1.4 & 1 & 0.4 & 5.1 & 4.9 & 5.0 & 0.1 & 6.5 & 7.2 & 121 & 6.9 & 0.5 & 29 & 0.1 \\
\hline 7 & PFPI Wire Ins & 540 & $\mathrm{~N}$ & 0.8 & 0.5 & 1.1 & 1.4 & 1 & 0.4 & 3.8 & 0.8 & 2.3 & 2.1 & 11.5 & 14.2 & 26.9 & 17.5 & 8.2 & $>30$ & 0 \\
\hline 21 & PFPI Wire Ins & 640 & $\mathrm{~N}$ & 0.8 & 0.6 & 0.8 & 1.2 & 1 & 0.2 & 0.8 & 0.1 & 0.5 & 0.5 & 12.5 & 10.7 & 34.5 & 19.2 & 13.3 & $>30$ & 0 \\
\hline 29 & PFPI Wire Ins & 640 & $\mathrm{~N}$ & 1.2 & 0.5 & 0.8 & 3.1 & 1 & 1 & 4.0 & 0.6 & & & 11.0 & 10 & 27.9 & 16.3 & 10.1 & 16.7 & 0.1 \\
\hline 31 & PFPI Wire Ins & 640 & $\mathrm{~N}$ & 1.2 & 0.6 & 1 & 2 & 1 & 1 & 2.2 & 0 & & & 8.4 & 6.3 & 3.4 & 6.0 & 2.5 & 19.5 & 0 \\
\hline 35 & PFPI Wire Ins & 540 & $\mathrm{~N}$ & 1.3 & 1.1 & 1.3 & 3.2 & 2 & 1 & 5.3 & 0.2 & & & 11.0 & 10.7 & 12.7 & 11.5 & 1.1 & 19.1 & 0 \\
\hline 8 & Circuit Brd & 540 & $\mathrm{~N}$ & 0.6 & 0.1 & nd & 1.6 & 1 & 1 & 14.1 & 0.6 & & & 0.6 & 0.9 & 4 & 1.8 & 1.9 & 2.5 & 1.7 \\
\hline 10 & Circuit Brd & 640 & $\mathrm{~N}$ & 0.7 & nd & nd & 2.1 & 1 & 1 & 18.5 & 0.8 & & & 1.0 & 0.5 & 7.5 & 0.75 & 0.4 & 1.5 & 4.9 \\
\hline 23 & Circuit Brd & 640 & $\mathrm{~N}$ & 0.4 & 0.1 & 0.4 & 1.1 & 0 & 0.4 & 17.8 & 0.3 & & & 1.4 & 1.0 & 7.8 & 1.2 & 0.3 & 5.2 & 4.5 \\
\hline 27 & Circuit Brd & 340 & $\mathrm{~N}$ & 1 & 0.1 & nd* & 2.8 & 1 & 1 & 14.1 & -- & & & 0.6 & 0.5 & -- & 0.6 & 0.1 & $<0.1$ & -- \\
\hline 34 & Circuit Brd & 430 & $\mathrm{~N}$ & 0.8 & 0.1 & nd & 2 & 1 & 1 & 25.5 & 0.2 & & & 0.2 & 0 & 0.9 & 0.4 & 0.5 & 0 & 1.0 \\
\hline 9 & $100 \%$ TFE & 540 & $\mathrm{~N}$ & 0.2 & 0.1 & nd & 1.6 & 1 & 1 & 3.4 & 1 & & & 3.9 & 6.9 & 186 & 5.4 & 2.1 & 21 & 0.4 \\
\hline 15 & $100 \%$ TFE & 640 & $\mathrm{~N}$ & 0 & nd & nd & 0.8 & 0 & 1 & 1.3 & 0 & & & 2.9 & 4.1 & 146 & 3.5 & 0.8 & 27 & 0 \\
\hline 20 & $100 \%$ PTFE & 540 & $\mathrm{~N}$ & 0.2 & 0.2 & nd & 0.2 & 0 & 0.0 & 0.2 & 0.1 & & & 1.3 & 3.5 & 84.8 & 2.4 & 1.6 & 8.3 & 0 \\
\hline 30 & $100 \%$ TFE & 640 & $\mathrm{~N}$ & 0 & 0.1 & 0.8 & 0.8 & 0 & 0.4 & 2.1 & 0 & & & 3.5 & 6.4 & 125 & 5.0 & 2.1 & 14.4 & 0 \\
\hline 42 & $100 \%$ TFE & 640 & $\mathrm{~N}$ & 0 & nd & 1.4 & 0 & 0 & 1 & 1.2 & 0.6 & & & 1.6 & 3.3 & 37.3 & 2.5 & 1.2 & 8.8 & 0 \\
\hline 22 & $90 \% \mathrm{~T} / 10 \% \mathrm{~K}$ & 640 & $\mathrm{~N}$ & 0.8 & 0.3 & 0.9 & 0 & 0 & 0.4 & 0.6 & 0 & & & 3.9 & 4.4 & 139.2 & 4.2 & 0.4 & 25 & 0 \\
\hline 36 & $90 \% \mathrm{~T} / 10 \% \mathrm{~K}$ & 640 & $\mathrm{~N}$ & 1 & 0.5 & 1.4 & 2.5 & 1 & 1 & 2.8 & 0.2 & & & 3.9 & 6.4 & 37.6 & 5.2 & 1.8 & 0 & 0.1 \\
\hline 14 & $75 \% \mathrm{~T} / 25 \% \mathrm{~K}$ & 540 & $\mathrm{~N}$ & 0 & nd & nd & 0.8 & 0 & 1 & 1.2 & 0.3 & & & 2.5 & 3.4 & 27.3 & 3.0 & 0.6 & 19.6 & 0 \\
\hline 19 & $75 \% \mathrm{~T} / 25 \% \mathrm{~K}$ & 640 & $\mathrm{~N}$ & 2.2 & 1.1 & 2.6 & 3.3 & 2 & 1 & 1.2 & 0.2 & & & 5 & 6.5 & 37 & 5.8 & 1.1 & 27.4 & 0 \\
\hline 32 & $75 \% \mathrm{~T} / 25 \% \mathrm{~K}$ & 640 & $\mathrm{~N}$ & 1.7 & 1.0 & 2.9 & 2.8 & 2 & 1 & 2.1 & -- & & & 5 & 5.6 & -- & 5.3 & 0.4 & -- & -- \\
\hline 12 & $50 \% \mathrm{~T} / 50 \% \mathrm{~K}$ & 540 & $\mathrm{~N}$ & 0.6 & nd & 0.4 & 1 & 1 & 0.3 & 1.3 & 0.4 & & & 2.2 & 2.4 & 73.4 & 2.3 & 0.1 & 11.2 & 0 \\
\hline 17 & $50 \% \mathrm{~T} / 50 \% \mathrm{~K}$ & 640 & $\mathrm{~N}$ & 3.6 & 2.7 & 4.5 & 5.5 & 4 & 1 & 2.1 & 0.4 & & & 3.9 & 5.3 & 71.3 & 4.6 & 1.0 & 21.8 & 0 \\
\hline 25 & $50 \% \mathrm{~T} / 50 \% \mathrm{~K}$ & 640 & $\mathrm{~N}$ & 2.6 & 2.3 & 3.3 & 3.4 & 3 & 0.5 & 2.6 & 0.2 & & & 3.9 & 4.5 & 26.7 & 4.2 & 0.4 & 14.3 & 0 \\
\hline 13 & $25 \% \mathrm{~T} / 75 \% \mathrm{~K}$ & 540 & $\mathrm{~N}$ & 0 & nd & nd & 0.8 & 0 & 1 & 1.0 & 0.2 & & & 1.2 & 1.0 & 17.4 & 1.1 & 0.1 & 8.4 & 0 \\
\hline 18 & $25 \% \mathrm{~T} / 75 \% \mathrm{~K}$ & 640 & $\mathrm{~N}$ & 3.8 & 3.0 & 5 & 5.7 & 4 & 1 & 1.9 & 0.3 & & & 2.9 & 2.6 & 38.1 & 2.8 & 0.2 & 15.5 & 0 \\
\hline 38 & $25 \% \mathrm{~T} / 75 \% \mathrm{~K}$ & 640 & $\mathrm{~N}$ & 1.7 & 1.5 & 2 & 2.6 & 2 & 0.5 & 0.9 & 0.3 & & & 1.8 & 1.7 & 19.1 & 1.8 & 0.1 & 4.5 & 0 \\
\hline 43 & $25 \% \mathrm{~T} / 75 \% \mathrm{~K}$ & 540 & $\mathrm{~N}$ & 7.5 & 7.9 & 11.8 & 11.8 & 10 & 2 & 3.2 & 0.2 & & & 5.2 & 6 & 9 & 6.7 & 2.0 & 8.8 & 0 \\
\hline 24 & $10 \% \mathrm{~T} / 90 \% \mathrm{~K}$ & 640 & $\mathrm{~N}$ & 1.8 & 1.4 & 2.2 & 1.1 & 2 & 0 & 3.3 & 0.1 & & & 1.2 & 1.2 & 4.9 & 2.4 & 2.1 & 4 & 0 \\
\hline 37 & $10 \% \mathrm{~T} / 90 \% \mathrm{~K}$ & 640 & $\mathrm{~N}$ & 2.7 & 2.8 & 3.8 & 5.1 & 4 & 1 & 3.1 & 0.7 & & & 1.7 & 1.5 & 1 & 1.4 & 0.4 & 0 & 0.1 \\
\hline 11 & 100\%Kapton & 540 & $\mathrm{~N}$ & 4.2 & 3.4 & 5.6 & 5.9 & 5 & 1 & 3.3 & 0.2 & & & 0 & 0 & 0.4 & 0.1 & 0.2 & 0 & 0 \\
\hline 16 & 100\%Kapton & 640 & $\mathrm{~N}$ & 5.3 & 4.2 & 7.2 & 7.7 & 6 & 2 & 3.6 & 0.2 & & & 0.5 & 0.5 & 4.1 & 1.7 & 2.1 & 3.5 & 0 \\
\hline 26 & 100\%Kapton & 640 & $\mathrm{~N}$ & 3.0 & 2.6 & 3.9 & 4.9 & 4 & 1 & 2.5 & 0.1 & & & 0.2 & 0 & 0.7 & 0.3 & 0.4 & 1 & 0 \\
\hline 40 & 100\%Kapton & 540 & $\mathrm{~N}$ & 0.9 & 0.3 & 0.5 & 2 & 1 & 1 & 2.1 & 0 & & & 0 & 0 & 0.8 & 0.3 & 0.5 & 0 & 0 \\
\hline 41 & 100\%Kapton & 540 & $\mathrm{~N}$ & 5.8 & 5.6 & 8 & 9.2 & 7 & 2 & 3.4 & 0.1 & & & 0 & 0 & 0.4 & 0.1 & 0.2 & 0 & 0 \\
\hline
\end{tabular}

Shading denotes anomaly due to run sequence error or inadvertent (self) ignition (omitted from calculations)

$\mathrm{XX}$ Boxed values are omitted from average and standard deviation calculation. Conclusions on sensor performance should not

be drawn at this time until further analysis is performed.

18

American Institute of Aeronautics and Astronautics 
Appendix C. Carbon Monoxide data from all sources for the September 2012 test (in ppm)

\begin{tabular}{|c|c|c|c|c|c|c|c|c|c|c|c|c|c|c|c|c|}
\hline & Fuel & Temp & Date & Time & Ash & & Draeger & Vista & Makel & Makel & Makel & Makel & WSTF & Run & Run & Fuel \\
\hline Run \# & $0.5 \mathrm{~g}$ & C & & local & g & CSA-CP & Xam5600 & COMA & Fixed-L & Fixed-H & Port-L & Port-H & PacIII & Avg & Std Dev & Stats \\
\hline 1 & Nomex & 640 & 10-Sep & $2: 44$ & 0.028 & 89 & 84 & 87 & 83 & 92 & 98 & 154 & 92 & 89 & 5 & \\
\hline 2 & $"$ & $"$ & $"$ & $3: 11$ & 0.046 & 118 & 112 & 129 & 125 & 103 & 152 & 110 & 127 & 122 & 15 & \\
\hline 3 & $"$ & $"$ & $"$ & $3: 34$ & 0.045 & 119 & 116 & 161 & 118 & 105 & 146 & 114 & 130 & 126 & 19 & \\
\hline 4 & $"$ & $"$ & $"$ & $4: 00$ & 0.014 & 92 & 92 & 121 & 92 & 113 & 90 & 99 & 104 & 100 & 11 & \\
\hline 5 & $"$ & $"$ & $"$ & $4: 23$ & 0.042 & 100 & 102 & 116 & 112 & 127 & 55 & 99 & 111 & 110 & 10 & \\
\hline 6 & Nomex & 640 & 11-Sep & $8: 54$ & 0.153 & 65 & 60 & 52 & 65 & 101 & 68 & 96 & 68 & & & \\
\hline 7 & " & $"$ & " & $9: 15$ & 0.091 & 105 & 100 & 87 & 93 & 108 & 102 & 84 & 113 & 99 & 10 & \\
\hline & & & excl \#6 & Avg & & 104 & 101 & 117 & 104 & 108 & 118 & 101 & 113 & & & 108 \\
\hline & & & excl \#6 & StdDev & & 13 & 12 & 28 & 17 & 12 & 29 & 12 & 14 & & & 18 \\
\hline 8 & M22759 ins & 640 & " & $9: 36$ & 0.046 & 53 & 54 & 44 & 47 & 76 & 32 & 70 & 58 & & & \\
\hline 9 & $"$ & $"$ & $"$ & $10: 06$ & 0.021 & 76 & 78 & 59 & 82 & 81 & 74 & 85 & 82 & 77 & 8 & \\
\hline 10 & $"$ & $"$ & $"$ & $10: 30$ & 0.017 & 72 & 72 & 55 & 83 & 73 & 79 & 76 & 79 & 74 & 8 & \\
\hline 11 & $"$ & $"$ & $"$ & $10: 53$ & 0.021 & 78 & 80 & 61 & 90 & 65 & 59 & 62 & 85 & 73 & 12 & \\
\hline 12 & $"$ & $"$ & $"$ & $11: 16$ & 0.030 & 68 & 72 & 56 & 90 & 69 & 75 & 70 & 78 & 72 & 10 & \\
\hline 13 & $"$ & $"$ & $"$ & $11: 37$ & 0.017 & 72 & 76 & 60 & 90 & 69 & 75 & 70 & 82 & 74 & 9 & \\
\hline & & & excl \#8 & Avg & & 73 & 76 & 58 & 87 & 71 & 72 & 73 & 81 & & & 74 \\
\hline & & & excl \#8 & StdDev & & 4 & 4 & 3 & 4 & 6 & 8 & 9 & 3 & & & 9 \\
\hline 14 & PTFE granules & 640 & $"$ & $2: 25$ & 0.041 & 9 & 14 & 10 & 7 & 8 & 11 & 3 & 14 & 10 & 3 & \\
\hline 15 & $"$ & $"$ & $"$ & $2: 48$ & 0.014 & 10 & 14 & 9 & 9 & 3 & 9 & 5 & 14 & 10 & 3 & \\
\hline 16 & $"$ & $"$ & $"$ & $3: 13$ & 0.010 & 4 & 8 & 5 & 6 & 7 & 11 & 5 & 7 & 7 & 2 & \\
\hline 17 & $"$ & $"$ & $"$ & $3: 38$ & 0.015 & 8 & 12 & 8 & 12 & 10 & 14 & 7 & 11 & 10 & 2 & \\
\hline 18 & Kapton chips & 640 & $"$ & $4: 07$ & 0.227 & 266 & 268 & 215 & 295 & 226 & 206 & 205 & 285 & 246 & 37 & \\
\hline 19 & $"$ & $"$ & $"$ & $4: 31$ & 0.278 & 233 & 224 & 187 & 244 & 218 & 108 & 128 & 259 & 228 & 25 & \\
\hline 20 & $"$ & $"$ & $"$ & $4: 52$ & 0.251 & 294 & 282 & 239 & 293 & 316 & 131 & 168 & 324 & 291 & 30 & \\
\hline 21 & Kapton powder & 640 & 12-Sep & $9: 10$ & 0.126 & 292 & 272 & 232 & 292 & 273 & 218 & 301 & 325 & 276 & 36 & \\
\hline 22 & " & $"$ & $"$ & $9: 36$ & 0.112 & 272 & 270 & 211 & 261 & 301 & 218 & 214 & 389 & 250 & 35 & \\
\hline & & \multicolumn{2}{|c|}{ All Kapton } & Avg & & 271 & 263 & 217 & 277 & 267 & 214 & 240 & 316 & & & 258 \\
\hline & & & & StdDev & & 25 & 23 & 20 & 23 & 44 & 7 & 53 & 49 & & & 38 \\
\hline 23 & PTFE powder & 640 & 12-Sep & $9: 56$ & 0 & 24 & 28 & 21 & 16 & 10 & 8 & 0 & 31 & & & \\
\hline 24 & $"$ & $"$ & $"$ & $10: 16$ & 0.006 & 7 & 12 & 6 & 7 & 8 & 5 & 8 & 10 & 8 & 2 & \\
\hline 25 & $"$ & $"$ & $"$ & $10: 37$ & 0.008 & 8 & 14 & 8 & 10 & 8 & 11 & 11 & 11 & 10 & 2 & \\
\hline \multirow[t]{3}{*}{26} & $"$ & $"$ & $"$ & $10: 56$ & 0.009 & 9 & 14 & 10 & 12 & 8 & 11 & 11 & 12 & 11 & 2 & \\
\hline & & \multicolumn{2}{|c|}{ All PTFE excl \#23 } & Avg & & 8 & 13 & 8 & 9 & 8 & 10 & 8 & 11 & & & 9 \\
\hline & & & & StdDev & & 2 & 2 & 2 & 2 & 1 & 3 & 3 & 2 & & & 3 \\
\hline 27 & PCB & 340 & 12-Sep & $12: 42$ & 0.366 & 11 & 14 & 10 & 8 & 15 & -- & -- & 13 & 13 & 2 & \\
\hline 28 & $"$ & $"$ & $"$ & $1: 02$ & 0.352 & 20 & 22 & 16 & 19 & 29 & -- & -- & 23 & 22 & 4 & \\
\hline 29 & $"$ & 440 & $"$ & $1: 22$ & 0.344 & 23 & 26 & 19 & 26 & 32 & -- & -- & 26 & 25 & 4 & \\
\hline 30 & $"$ & $"$ & $"$ & $1: 42$ & 0.323 & 25 & 28 & 20 & 27 & 43 & -- & -- & 29 & 29 & 8 & \\
\hline 31 & $"$ & 540 & $"$ & $2: 07$ & 0.321 & 28 & 30 & 22 & 29 & 39 & -- & -- & 31 & 30 & 5 & \\
\hline 32 & $"$ & $"$ & $"$ & $2: 30$ & 0.335 & 25 & 28 & 22 & 27 & 35 & -- & -- & 29 & 28 & 4 & \\
\hline 33 & $"$ & 640 & $"$ & $2: 50$ & 0.308 & 36 & 38 & 27 & 43 & 40 & -- & -- & 40 & 37 & 6 & \\
\hline \multirow[t]{2}{*}{34} & $"$ & $"$ & $"$ & $3: 18$ & 0.302 & 34 & 36 & 27 & 41 & 36 & -- & -- & 38 & 35 & 5 & \\
\hline & \multicolumn{13}{|c|}{ Shading denotes anomaly due to run sequence error or inadvertent (self) ignition; data excluded from statistics } & \multicolumn{2}{|c|}{ PCB 640C Avg } & 36 \\
\hline$x X$ & Boxed values a & re omitted & from aver & age and $s$ & andard d & viation calc & sulation. Cons & Iusions o & n sensor $\mathrm{r}$ & cerforman & & & & CB 640 & C StdDev & 5 \\
\hline
\end{tabular}

should not be drawn at this time until further analysis is performed.

19

American Institute of Aeronautics and Astronautics 
Appendix C continued ... (concentrations in ppm)

\begin{tabular}{|c|c|c|c|c|c|c|c|c|c|c|c|c|c|c|c|c|}
\hline & Fuel & Temp & Date & Time & Ash & & Draeger & Vista & Makel & Makel & Makel & Makel & WSTF & Run & Run & Fuel \\
\hline Run \# & $0.5 \mathrm{~g}$ & C & & local & g & CSA-CP & Xam5600 & COMA & Fixed-L & Fixed-H & Port-L & Port-H & PacIII & Avg & Std Dev & Stats \\
\hline 35 & $100 \%$ PVC & 640 & 12-Sep & $3: 36$ & 0.009 & 66 & 66 & 48 & -- & -- & -- & -- & 38 & 60 & 10 & \\
\hline 36 & $50 / 50 \mathrm{P} / \mathrm{K}$ & 640 & 13-Sep & $8: 38$ & 0.046 & 246 & 230 & 249 & 240 & 182 & 58 & 315 & 270 & 258 & 31 & \\
\hline 37 & $"$ & $"$ & $"$ & $8: 59$ & 0.061 & 253 & 246 & 256 & 265 & 236 & 211 & 278 & 283 & 254 & 23 & \\
\hline 38 & $"$ & $"$ & $"$ & $9: 18$ & 0.111 & 80 & 80 & 80 & 85 & 143 & 113 & 186 & & & & \\
\hline \multirow[t]{3}{*}{39} & $"$ & $"$ & $"$ & 9:35 & 0.042 & 286 & 280 & 298 & 330 & 271 & 357 & 245 & 321 & 299 & 36 & \\
\hline & & & & Avg & & 262 & 252 & 268 & 278 & 254 & 284 & 279 & 291 & & & 271 \\
\hline & & & & StdDev & & 21 & 26 & 27 & 46 & 25 & 103 & 35 & 27 & & & 36 \\
\hline 40 & $25 / 75 \mathrm{P} / \mathrm{K}$ & 640 & " & $9: 54$ & 0.092 & 301 & 286 & 311 & 340 & 248 & 357 & 218 & 334 & 311 & 37 & \\
\hline 41 & $"$ & $"$ & $"$ & $10: 12$ & 0.074 & 378 & 356 & 398 & 419 & 344 & 378 & 288 & 426 & 373 & 45 & \\
\hline 42 & $"$ & $"$ & " & $10: 31$ & 0.128 & 156 & 138 & 132 & 123 & 159 & 107 & 166 & 144 & & & \\
\hline \multirow[t]{3}{*}{43} & $"$ & $"$ & $"$ & $10: 54$ & 0.074 & 370 & 346 & 386 & 361 & 333 & 297 & 249 & 422 & 346 & 54 & \\
\hline & & & & Avg & & 350 & 329 & 365 & 373 & 308 & 344 & 269 & 394 & & & 345 \\
\hline & & & & StdDev & & 42 & 38 & 47 & 41 & 53 & 42 & 28 & 52 & & & 51 \\
\hline 44 & $10 / 90 \mathrm{P} / \mathrm{K}$ & 640 & $"$ & $12: 29$ & 0.088 & 392 & 370 & 415 & 353 & 180 & 182 & 202 & 436 & 393 & 33 & \\
\hline 45 & $"$ & $"$ & $"$ & $12: 48$ & 0.139 & 228 & 220 & 238 & 198 & 137 & 73 & 151 & 250 & & & \\
\hline \multirow[t]{3}{*}{46} & $"$ & $"$ & $"$ & 1:06 & 0.088 & 440 & 414 & 464 & 414 & 309 & 202 & 323 & 480 & 406 & 66 & \\
\hline & & & & Avg & & 416 & 392 & 439.5 & 384 & 309 & -- & 323 & 458 & & & 401 \\
\hline & & & & StdDev & & 34 & 31 & 35 & 43 & -- & -- & -- & 31 & & & 53 \\
\hline 47 & $75 / 25 \mathrm{P} / \mathrm{K}$ & 640 & $"$ & $1: 32$ & 0.031 & 138 & 134 & 148 & 117 & 126 & 38 & 128 & 154 & 135 & 13 & \\
\hline 48 & $"$ & $"$ & $"$ & $1: 50$ & 0.047 & 53 & 60 & 56 & 52 & 114 & 61 & 152 & 60 & & & \\
\hline 49 & $"$ & $"$ & $"$ & $2: 10$ & 0.011 & 95 & 94 & 103 & 89 & 94 & 98 & 112 & 107 & 99 & 8 & \\
\hline \multirow[t]{3}{*}{50} & $"$ & $"$ & $"$ & $2: 30$ & 0.021 & 120 & 118 & 131 & 124 & 124 & 118 & 139 & 135 & 126 & 8 & \\
\hline & & & & Avg & & 118 & 115 & 127 & 110 & 115 & 108 & 126 & 132 & & & 119 \\
\hline & & & & StdDev & & 22 & 20 & 23 & 19 & 18 & 14 & 14 & 24 & & & 18 \\
\hline 51 & $90 / 10 \mathrm{P} / \mathrm{K}$ & 640 & $"$ & $2: 53$ & 0.016 & 77 & 76 & 83 & 72 & 81 & 55 & 87 & 87 & 77 & 10 & \\
\hline 52 & $"$ & $"$ & $"$ & $3: 12$ & 0.007 & 73 & 72 & 78 & 69 & 71 & 63 & 61 & 81 & 71 & 7 & \\
\hline \multirow[t]{3}{*}{53} & $"$ & $"$ & $"$ & $3: 30$ & 0.010 & 55 & 56 & 59 & 55 & 72 & 40 & 53 & 63 & 59 & 7 & \\
\hline & & & & Avg & & 68 & 68 & 73 & 65 & 75 & 53 & 67 & 77 & & & 68 \\
\hline & & & & StdDev & & 12 & 11 & 13 & 9 & 6 & 12 & 18 & 12 & & & 12 \\
\hline 54 & 90/10 P/PVC & 640 & $"$ & $3: 47$ & 0.002 & 37 & 38 & 39 & 41 & 29 & 35 & 33 & 43 & 37 & 4 & \\
\hline 55 & $"$ & $"$ & $"$ & 4:06 & 0.002 & 24 & 26 & 28 & 31 & 33 & 29 & 31 & 30 & 29 & 3 & \\
\hline \multirow[t]{3}{*}{56} & $"$ & $"$ & $"$ & $4: 24$ & 0.001 & 27 & 28 & 28 & 39 & 27 & 33 & 28 & 32 & 30 & 4 & \\
\hline & & & & Avg & & 29 & 31 & 32 & 37 & 30 & 32 & 31 & 35 & & & 32 \\
\hline & & & & StdDev & & 7 & 6 & 6 & 5 & 3 & 3 & 3 & 7 & & & 5 \\
\hline 57 & $\mathrm{PCB}+\mathrm{PVC} 1$ & 640 & 14-Sep & $8: 33$ & 0.297 & 47 & 44 & 49 & 46 & 56 & 0 & 67 & 49 & 51 & 8 & \\
\hline 58 & $"$ & $"$ & $"$ & $8: 56$ & 0.347 & 43 & 42 & 46 & 44 & 57 & 35 & 61 & 47 & 47 & 8 & 52 \\
\hline 59 & $"$ & $"$ & $"$ & $9: 17$ & 0.312 & 57 & 50 & 63 & 58 & 68 & 54 & 58 & 55 & 58 & 6 & 8 \\
\hline 60 & $\mathrm{PCB}+\mathrm{PVC} 2$ & 640 & $"$ & 9:39 & 0.303 & 55 & 52 & -- & 61 & 73 & 50 & 59 & 59 & 58 & 8 & 61 \\
\hline 61 & $"$ & $"$ & $"$ & $10: 05$ & 0.301 & 62 & 62 & 65 & 69 & 72 & 47 & 61 & 69 & 63 & 8 & 8 \\
\hline \multirow[t]{2}{*}{62} & PTFE/PVC2 & $"$ & $"$ & $10: 28$ & 0.004 & 34 & 36 & 38 & 29 & 27 & 29 & 33 & 40 & 33 & 5 & \\
\hline & \multicolumn{13}{|c|}{ Shading denotes anomaly due to run sequence error or inadvertent (self) ignition; data excluded from statistics } & & & \\
\hline $\mathrm{XX}$ & Boxed values & mittec & from av & ge and & andarc & iation & ulation & clusio & on se & perf & nce & uld & e & inn a & lis time & furth \\
\hline
\end{tabular}


Appendix D. HCN and acid gas results for the Sep 2012 test (in ppm)

\begin{tabular}{|c|c|c|c|c|c|c|c|c|c|c|c|c|c|c|c|c|c|c|c|c|}
\hline & & & $\mathrm{HCN}$ & & & & & & $\mathrm{HCL}$ & & & & & $\mathrm{HF}$ & & & & & $H X$ & $\mathrm{HBr}$ \\
\hline Run & Fuel & $T / C$ & Draeger & CSA-CP & PAS & PacllI & Avg & StdDev & CSA-CP & HCPM & Wet Trap & Avg & StdDev & HCPM & Hfiii & Wet Trap & Avg & StdDev & PacllI & Wet Trap \\
\hline 1 & Nomex & 640 & 5.7 & 5.7 & 8.4 & 6.7 & 7 & 2 & 20 & nd & 0.2 & & & nd & nd & nd & nd & -- & nd & \\
\hline 2 & $"$ & $"$ & 6.4 & 6.2 & 9.4 & 7.6 & 7 & 1 & 25 & nd & nd & & & nd & nd & nd & nd & -- & nd & \\
\hline 3 & $"$ & $"$ & 7.8 & 7.3 & 10.8 & 8.7 & 9 & 2 & 26 & nd & 0.3 & & & nd & nd & nd & nd & -- & nd & \\
\hline 4 & $"$ & $"$ & 5.4 & 5.3 & 7.3 & 6.3 & 6 & 1 & 26.5 & nd & 0.3 & & & nd & nd & nd & nd & -- & nd & \\
\hline 5 & $"$ & $"$ & 6.1 & 5.9 & 8.7 & 7.1 & 7 & 1 & 28 & nd & 0.4 & & & nd & nd & nd & nd & -- & nd & \\
\hline 6 & $"$ & $"$ & 6.0 & 5.8 & 8.1 & 7.2 & 7 & 1 & 18.1 & nd & 0.1 & & & nd & nd & nd & nd & -- & 7.1 & \\
\hline \multirow[t]{3}{*}{7} & $"$ & $"$ & 8.1 & 7.8 & 10.4 & 9.5 & 9 & 1 & 25 & nd & 0.1 & & & nd & nd & nd & nd & -- & 19.3 & \\
\hline & & Avg & 6.5 & 6.3 & 9.0 & 7.6 & & 7.3 & & & & & & & & & & & & \\
\hline & & StDev & 1.0 & 0.9 & 1.3 & 1.1 & & 1.5 & & & & & & & & & & & & \\
\hline 8 & M22759 ins & 640 & 3.4 & 3.3 & 4.4 & 4.2 & 4 & 1 & 6.8 & nd & 0.0 & & & 7.1 & 4 & 9.2 & 7 & 3 & 29.4 & \\
\hline 9 & " & $"$ & 3.4 & 3.1 & 4.4 & 4.2 & 4 & 1 & 6.5 & nd & 1.4 & & & 8 & 6.5 & 11.2 & 9 & 2 & 30.0 & \\
\hline 10 & $"$ & $"$ & 4.0 & 3.6 & 4.9 & 4.8 & 4 & 1 & 7.7 & nd & 1.2 & & & 10.5 & 8.8 & 27.9 & 10 & 1 & 30.0 & \\
\hline 11 & $"$ & $"$ & 3.8 & 3.4 & 4.7 & 4.7 & 4 & 1 & 7.2 & nd & 0.1 & & & 12.3 & 11.3 & 20.5 & 15 & 5 & 30.0 & \\
\hline 12 & $"$ & $"$ & 3.9 & 3.5 & 5 & 4.8 & 4 & 1 & 6.6 & nd & 0.1 & & & 13.3 & 12.2 & 24 & 13 & 1 & 27.6 & \\
\hline \multirow[t]{3}{*}{13} & $"$ & $"$ & 3.7 & 3.1 & 4.7 & 4.6 & 4 & 1 & 5.6 & nd & 0.1 & & & 12.8 & 14.2 & 13.9 & 14 & 1 & 30.0 & \\
\hline & & Avg & 3.7 & 3.3 & 4.7 & 4.6 & & 4.1 & 6.7 & nd & 0.5 & & & 10.7 & 9.5 & 13.7 & & 11 & 29.5 & \\
\hline & & StDev & 0.3 & 0.2 & 0.2 & 0.3 & & 0.6 & 0.7 & nd & 0.6 & & & 2.6 & 3.8 & 4.9 & & 4 & 1.0 & \\
\hline 14 & PTFE granules & 640 & nd & 0.1 & nd & 0.6 & & & 1.3 & nd & & & & 10.1 & 12.9 & & 12 & 2 & 30 & \\
\hline 15 & " & " & nd & 0 & nd & 0.3 & & & 1.3 & nd & 0.1 & & & 14.7 & 17.4 & 45.7 & 16 & 2 & 30 & \\
\hline 16 & $"$ & " & nd & -0.2 & nd & 0.3 & & & 1.1 & nd & 0.1 & & & 8.6 & 15.1 & 21.6 & 15 & 7 & 0 & \\
\hline 17 & $"$ & $"$ & nd & -0.2 & nd & 0.2 & & & 1.2 & nd & & & & 10.7 & 15.2 & & 13 & 3 & 0 & \\
\hline 18 & Kapton chips & 640 & 10.2 & 8.9 & 13.6 & 12.0 & 11 & 2 & 10 & nd & nd & & & 1.7 & 1.8 & 3.4 & 2 & 1 & nd & \\
\hline 19 & $"$ & $"$ & 7.7 & 6.7 & 9.6 & 9.2 & 8 & 1 & 8.7 & nd & nd & & & 0.8 & nd & 1.4 & 1 & nd & nd & \\
\hline 20 & $"$ & $"$ & 12.3 & 11.2 & 15.6 & 14.2 & 13 & 2 & 12.3 & nd & 0.2 & & & 0.6 & nd & 1.0 & 1 & nd & nd & \\
\hline 21 & Kapton powder & 640 & 8.1 & 8.4 & 11.6 & 10.2 & 10 & 2 & 14 & nd & nd & & & nd & nd & & & & nd & \\
\hline \multirow[t]{3}{*}{22} & " & $"$ & 7.5 & 7.8 & 10.7 & 9.9 & 9 & 2 & 15 & nd & nd & & & nd & nd & & & & nd & \\
\hline & all Kapton & Avg & 9.2 & 8.6 & 12.2 & 11.1 & & \begin{tabular}{|l|}
10.3 \\
\end{tabular} & & nd & nd & & nd & & & & & 1 & & \\
\hline & & StDev & 2.1 & 1.7 & 2.4 & 2.0 & & 2.4 & & & & & & & & & & 0.8 & & \\
\hline 23 & PTFE powder & 640 & nd & 0.1 & nd & 0.5 & & & 2.0 & nd & 0.1 & & & 7.2 & 7.6 & 14.6 & 10 & 4 & 17.6 & \\
\hline 24 & $"$ & $"$ & nd & -0.3 & nd & 0.4 & & & 1.4 & nd & 0.0 & & & 7 & 11.3 & 32.2 & 9 & 3 & 12.7 & \\
\hline 25 & $"$ & $"$ & nd & -0.1 & nd & 0.3 & & & 1.3 & nd & 0.2 & & & 9.5 & 14.4 & 24.5 & 16 & 8 & 17.3 & \\
\hline \multirow[t]{3}{*}{26} & $"$ & $"$ & nd & -0.2 & nd & 0.1 & & & 1.3 & nd & 0.1 & & & 11.8 & 17.6 & 22.2 & 17 & 5 & 19.4 & 0.9 \\
\hline & all PTFE & Avg & nd & nd & nd & 0.3 & & & & nd & 0.1 & & nd & 10.0 & 13.9 & 20.7 & & 13 & 16.8 & \\
\hline & & StDev & & & & 0.2 & & & & & & & & 2.5 & 3.3 & 4.3 & & 5 & 2.9 & \\
\hline 27 & PCB & 340 & nd & 0.1 & nd & 0.3 & & & 10.2 & nd & 0.0 & & & 0.5 & 0.7 & & 0.6 & 0.1 & nd & nd \\
\hline 28 & $"$ & $"$ & nd & 0.1 & nd & 0.3 & & & 13.5 & nd & & & & 0.3 & 0.7 & & 0.5 & 0.3 & nd & \\
\hline 29 & $"$ & 440 & nd & 0.1 & nd & 0.3 & & & 17 & nd & 0.1 & & & 0.3 & 0.4 & 1.5 & 0.7 & 0.7 & nd & 1.8 \\
\hline 30 & $"$ & $"$ & nd & 0.1 & nd & 0.4 & & & 16.2 & nd & 0.0 & & & 0.4 & 0.1 & 0.9 & 0.5 & 0.4 & nd & 0.8 \\
\hline 31 & $"$ & 540 & nd & 0.1 & nd & 0.4 & & & 17 & nd & 0.2 & & & 0.4 & 0.1 & 1.1 & 0.5 & 0.5 & 0.8 & 2.3 \\
\hline 32 & " & $"$ & nd & 0.1 & nd & 0.4 & & & 16.6 & nd & 0.1 & & & 0.4 & 0.5 & 1.0 & 0.6 & 0.3 & 0.9 & 2.2 \\
\hline 33 & $"$ & 640 & nd & 0.1 & nd & 0.5 & & & 19.8 & nd & 0.2 & & & 0.4 & 0.4 & 1.5 & 0.8 & 0.6 & 1.3 & 1.0 \\
\hline \multirow[t]{4}{*}{34} & $"$ & $"$ & nd & 0.1 & nd & 0.6 & & & 18 & nd & 0.1 & & & 0.4 & 0.3 & 1.2 & 0.6 & 0.5 & 0.9 & 1.0 \\
\hline & & Avg & & & & & & nd & & & & & nd & & & \multirow{2}{*}{\multicolumn{2}{|c|}{ avg at $640 \mathrm{C}$}} & 0.7 & & 1.0 \\
\hline & & StDev & & & & & & & & & & & & & & & & 0.5 & & \\
\hline & Shading den & otes an & omaly c & de to $\mathrm{ru}$ & sequ & ence e & ror & nadverte & ent (sel & ignitior & data ex & & $\mathrm{mst}$ & istics & & & & & & \\
\hline$X X$ & Boxed value & s are on & mitted fr & m aver & ge and & d stano & rd dev & jiation ce & calculati & ר. Concl & lusions or & en & perf & pance & ould & be dra & & & & \\
\hline
\end{tabular}

21

American Institute of Aeronautics and Astronautics 
Appendix D continued.... (concentrations in ppm)

\begin{tabular}{|c|c|c|c|c|c|c|c|c|c|c|c|c|c|c|c|c|c|c|c|c|}
\hline & & & $\mathrm{HCN}$ & & & & & & $\mathrm{HCL}$ & & & & & HF & & & & & HX & $\begin{array}{l}\mathrm{HBr} \\
\mathrm{Bet}\end{array}$ \\
\hline Run \# & Fuel & $T / C$ & Draeger & CSA-CP & PAS & PacllI & Avg & StdDev & CSA-CP & HCPM & Wet Trap & Avg & StdDev & HCPM & Hfiii & Wet Trap & Avg & StdDev & Paclll & \\
\hline 35 & $100 \%$ PVC & 640 & 7.3 & 0.2 & nd & 8.4 & 4 & & $>99$ & 252 & 59.9 & & & 4.4 & 6.3 & 14 & 8 & & $>30$ & 0.4 \\
\hline 36 & $50 / 50 \mathrm{P} / \mathrm{K}$ & 640 & 5.9 & 6.2 & 8.7 & 7.6 & 7 & 1 & 6 & 0.6 & 0.6 & 0.6 & & 3.3 & 3.3 & 19.3 & & & 4.7 & 0.2 \\
\hline 37 & $"$ & $"$ & 8.9 & 8.2 & 11.6 & 9.3 & 10 & 1 & 6.6 & 0.6 & 0.5 & 0.6 & & 6.5 & 6.9 & 21.6 & & & 9.0 & 0.1 \\
\hline 38 & $"$ & $"$ & 3.5 & 3.3 & 4.5 & & & & 7.7 & 0.4 & & & & 5.3 & 6.1 & & & & & \\
\hline \multirow[t]{3}{*}{39} & $"$ & $"$ & 10.2 & 9.2 & 13.4 & 12 & 11 & 2 & 8.2 & 0.8 & 0.7 & 0.8 & & 8.6 & 10.3 & 24.4 & & & 11.5 & 0.1 \\
\hline & & Avg & 8 & 7.9 & 11.2 & 9.6 & & 9.3 & & & & & 0.6 & & & & & & & 0.1 \\
\hline & & StDev & 2 & 1.5 & 2.4 & 2.2 & & 2.3 & & & & & 0.1 & & & & & & & \\
\hline 40 & $25 / 75 \mathrm{P} / \mathrm{K}$ & 640 & 8.9 & 8.2 & 12.2 & 10.4 & 10 & 2 & 9.5 & nd & 0.7 & & & 7.6 & 9.3 & 11.3 & & & 9.4 & nd \\
\hline 41 & $"$ & $"$ & 11.8 & 10.4 & 16.2 & 13.6 & 13 & 3 & 10.5 & nd & 0.5 & & & 7.8 & 9.9 & 8.9 & & & 5.3 & nd \\
\hline 42 & $"$ & $"$ & 4.1 & 4.1 & 5 & 4.4 & & & 6.2 & nd & 0.1 & & & 7.8 & 9.4 & 2.8 & & & 4.5 & nd \\
\hline \multirow[t]{3}{*}{43} & $"$ & $"$ & 11.6 & 10.4 & 15.6 & 13.1 & 13 & 2 & 10 & nd & 0.5 & & & 8.2 & 10 & 9.5 & & & 5.1 & nd \\
\hline & & Avg & 10.8 & 9.7 & 14.7 & 12.4 & & 11.9 & & & & & & & & & & 9.2 & & nd \\
\hline & & StDev & 1.6 & 1.3 & 2.2 & 1.7 & & 2.5 & & & & & & & & & & 1.2 & & \\
\hline 44 & $10 / 90 \mathrm{P} / \mathrm{K}$ & 640 & 11.8 & 11.2 & 15.9 & 13.4 & & & 9.1 & nd & 0.2 & & & 2.2 & 2.4 & 4.5 & & & 1.6 & nd \\
\hline 45 & $"$ & $"$ & 7.2 & 7.0 & 9.6 & 8.2 & & & 6.9 & nd & nd & & & 2.4 & 2.7 & 2.4 & & & 1.7 & nd \\
\hline \multirow[t]{3}{*}{46} & $"$ & $"$ & 14.4 & 13.1 & 19.2 & 15.2 & & & 9.3 & nd & 0.1 & & & 2.5 & 3 & 3.3 & & & 1.7 & nd \\
\hline & & Avg & 13.1 & 12.2 & 17.6 & 14.3 & & 14.3 & & & & & nd & & & & & 3.0 & & nd \\
\hline & & StDev & 1.8 & 1.3 & 2.3 & 1.3 & & 2.5 & & & & & & & & & & & & \\
\hline 47 & $75 / 25 \mathrm{P} / \mathrm{K}$ & 640 & 5.5 & 4.6 & 7.2 & 6.0 & & & 4.8 & nd & 0.1 & & & 9.1 & 13.6 & 16.6 & & & 5.4 & nd \\
\hline 48 & $"$ & $"$ & 2.8 & 2.4 & 3.7 & 3.2 & & & 3.7 & 0.8 & 0.6 & & & 10 & 13 & 20.1 & & & 6.8 & nd \\
\hline 49 & $"$ & $"$ & 4.1 & 3.4 & 5.5 & 4.7 & & & 5 & 0.8 & 0.5 & & & 11.3 & 15.2 & 23.9 & & & 7.3 & nd \\
\hline \multirow[t]{3}{*}{50} & $"$ & $"$ & 4.3 & 3.7 & 5.7 & 4.9 & & & 5.7 & 0.4 & 0.4 & & & 14.3 & 18.7 & 23.9 & & & 9.0 & nd \\
\hline & & Avg & 4.6 & 3.9 & 6.1 & 5.2 & & 5.0 & & & & & 0.4 & & & & & & & nd \\
\hline & & StDev & 0.8 & 0.6 & 0.9 & 0.7 & & 1.1 & & & & & 0.3 & & & & & & & \\
\hline 51 & $90 / 10 \mathrm{P} / \mathrm{K}$ & 640 & 3.1 & 2.2 & 3.7 & 3.3 & & & 4.3 & 0.6 & 0.2 & & & 10 & 14.9 & 28.4 & & & 8.5 & nd \\
\hline 52 & $"$ & $"$ & 2.7 & 1.6 & 3.7 & 3.1 & & & 4.9 & 0.4 & & & & 15.3 & 21.4 & & & & 10.5 & nd \\
\hline \multirow[t]{3}{*}{53} & $"$ & $"$ & 2.3 & 1.3 & 3.2 & 2.8 & & & 4.5 & 0.6 & & & & 16.9 & 22.5 & & & & 10.8 & nd \\
\hline & & Avg & 2.7 & 1.7 & 3.5 & 3.1 & & 2.8 & & & & & 0.5 & & & & & & & nd \\
\hline & & StDev & 0.4 & 0.5 & 0.3 & 0.3 & & 0.8 & & & & & 0.2 & & & & & & & \\
\hline 54 & 90/10 P/PVC & 640 & 0.6 & 0 & nd & 0.6 & & & 26.5 & 25 & 6.4 & & & 17.9 & 24 & 29.4 & & & 14.3 & nd \\
\hline 55 & $"$ & $"$ & 0.6 & 0 & nd & 0.8 & & & 35 & 29.2 & 9.6 & & & 17.1 & 22.8 & 30.2 & & & 13.5 & nd \\
\hline \multirow[t]{3}{*}{56} & $"$ & $"$ & 0.6 & 0.1 & nd & 0.7 & & & 43 & 29.2 & 9.4 & & & 18.3 & 24 & 33 & & & 13.1 & nd \\
\hline & & Avg & 0.6 & 0.0 & nd & 0.7 & & 0.4 & & & & & 18.1 & & & & & & 13.6 & nd \\
\hline & & StDev & nd & 0.1 & & 0.1 & & 0.3 & & & & & 10.8 & & & & & & 0.6 & \\
\hline 57 & $\mathrm{PCB}+\mathrm{PVC} 1$ & 640 & nd & 0.2 & nd & 1.3 & & & 19 & 23 & 3.7 & & & 1.0 & 1.3 & 1.5 & & & 0.7 & 2 \\
\hline 58 & $"$ & $"$ & 0.5 & 0.2 & nd & 1.5 & & & 35 & 28.4 & 5.1 & & & 1.0 & 1.1 & 1.3 & & & 0.8 & 1 \\
\hline \multirow[t]{3}{*}{59} & $"$ & $"$ & 0.6 & 0.2 & nd & 1.9 & & & 44.7 & 29.4 & & & & 1.1 & 1.4 & & & & 0.7 & \\
\hline & & Avg & & & & & & 0.8 & & & & & & & & & & & & \\
\hline & & StDev & & & & & & 0.7 & & & & & & & & & & & & \\
\hline 60 & $\mathrm{PCB}+\mathrm{PVC2}$ & 640 & 1.3 & 0.2 & nd & 2.5 & & & 97 & 62.2 & 21.3 & & & 1.3 & 1.7 & 4 & & & 2.5 & 3.7 \\
\hline \multirow[t]{3}{*}{61} & $"$ & $"$ & 1.4 & 0.2 & nd & 2.5 & & & 86.5 & 60 & 15.1 & & & 1.2 & 1.5 & 1.5 & & & 2.6 & 1.1 \\
\hline & & Avg & & & & & & & & & & & & & & & & & & \\
\hline & & StDev & & & & & & & & & & & & & & & & & & \\
\hline 62 & PTFE/PVC2 & $"$ & 1.9 & 0.2 & nd & 2.5 & & & 99+ & 67.8 & & & & 7.2 & 8.6 & & & & 2.8 & \\
\hline
\end{tabular}
$\mathrm{XX}$ Boxed values are statistical outliers omitted from average and standard deviation calculation. Concilusions on sensor performance should not be drawn at this time until further 
Appendix E. Aerosol Mass Concentration and Ash Data for February/March 2012 Test

\begin{tabular}{|c|c|c|c|c|c|c|c|c|c|}
\hline \begin{tabular}{|l} 
Feb/Mar \\
2012 \\
TestDates \\
\end{tabular} & $\begin{array}{l}\text { Test } \\
\text { No. }\end{array}$ & Material & Temp, C & $\begin{array}{l}\text { TEOM Mass } \\
\text { Conc } \mathrm{mg} / \mathrm{m}^{\wedge} \mathbf{3}\end{array}$ & $\begin{array}{l}\text { TEOM Mass } \\
\text { Conc } \mathrm{g} / \mathrm{m}^{\wedge} 3 \\
\end{array}$ & $\begin{array}{c}\text { Thermal } \\
\text { Precipitator }\end{array}$ & \begin{tabular}{|c|} 
Aerosol \\
Number \\
Concentration, \\
$\# / \mathbf{c m}^{\wedge} 3$ \\
\end{tabular} & $\begin{array}{c}\text { Estimated } \\
\text { Mass of } \\
\text { Particles, g } \\
\end{array}$ & $\begin{array}{c}\text { Ash Mass, } \\
\mathrm{g}\end{array}$ \\
\hline \multirow[t]{2}{*}{$2 / 27 / 2012$} & 1 & Std Mix & 540 & 11.91 & 0.0119 & Y & & 0.0074 & 0.0119 \\
\hline & 2 & $"$ & 540 & 65.09 & 0.0651 & $Y$ & & 0.0405 & 0.0651 \\
\hline Day 1 & 3 & wire insulation & 540 & 6.80 & 0.0068 & $\mathrm{Y}$ & & 0.0042 & 0.0068 \\
\hline \multirow[t]{15}{*}{$2 / 28 / 2012$} & 4 & Std Mix & 540 & 106.52 & 0.1065 & $Y$ & $4.90 E+06$ & 0.0664 & 0.1065 \\
\hline & 5 & $"$ & 540 & 67.01 & 0.0670 & $Y$ & $4.33 E+06$ & 0.0417 & 0.0670 \\
\hline & 6 & wire insulation & 640 & 14.42 & 0.0144 & $Y$ & $3.31 E+06$ & 0.0090 & 0.0144 \\
\hline & 7 & $"$ & 540 & 10.16 & 0.0102 & & $3.28 E+06$ & 0.0063 & 0.0102 \\
\hline & 8 & Circuit Bd & 540 & 54.14 & 0.0541 & Y & $3.60 E+06$ & 0.0337 & 0.0541 \\
\hline & 9 & $100 \%$ TFE & 540 & 95.64 & 0.0956 & $Y$ & $4.30 E+06$ & 0.0596 & 0.0956 \\
\hline & 10 & Circuit Bd & 640 & 107.19 & 0.1072 & & $4.53 E+06$ & 0.0668 & 0.1072 \\
\hline & 11 & $100 \%$ Kapton & 540 & 7.21 & 0.0072 & $Y$ & $3.40 E+06$ & 0.0045 & 0.0072 \\
\hline & 12 & 50\%TFE 50\% Kap & 540 & 4.81 & 0.0048 & Y & $1.57 E+06$ & 0.0030 & 0.0048 \\
\hline & 13 & 25\%TFE 75\%Кар & 540 & 14.16 & 0.0142 & $Y$ & $1.24 \mathrm{E}+06$ & 0.0088 & 0.0142 \\
\hline & 14 & 75\%TFE 25\%Кар & 540 & 13.19 & 0.0132 & $Y$ & $1.83 \mathrm{E}+06$ & 0.0082 & 0.0132 \\
\hline & 15 & $100 \%$ TFE & 640 & 13.61 & 0.0136 & $Y$ & $2.44 \mathrm{E}+06$ & 0.0085 & 0.0136 \\
\hline & 16 & $100 \%$ Kapton & 640 & 12.84 & 0.0128 & $Y$ & & 0.0080 & 0.0128 \\
\hline & 17 & 50\%TFE 50\% Kap & 640 & 49.25 & 0.0492 & $Y$ & $2.33 E+06$ & 0.0307 & 0.0492 \\
\hline & 18 & 75\%TFE 25\%Кар & 640 & 29.57 & 0.0296 & Y & $2.19 E+06$ & 0.0184 & 0.0296 \\
\hline Day 2 & 19 & 75\%TFE 25\%Кар & 640 & 22.76 & 0.0228 & $\mathrm{Y}$ & $2.03 E+06$ & 0.0142 & 0.0228 \\
\hline \multirow[t]{12}{*}{ 2/29/2012 } & 20 & $100 \%$ TFE & 540 & 2.40 & 0.0024 & $Y$ & $1.16 E+06$ & 0.0015 & 0.0024 \\
\hline & 21 & wire insulation & 640 & 21.06 & 0.0211 & & $2.41 E+06$ & 0.0131 & 0.0211 \\
\hline & 22 & 90\%TFE 10\%Кар & 640 & 8.35 & 0.0083 & & $1.95 E+06$ & 0.0052 & 0.0083 \\
\hline & 23 & Circuit Bd & 640 & 77.09 & 0.0771 & $Y$ & 4.17E+06 & 0.0480 & 0.0771 \\
\hline & 24 & 10\%TFE 90\%Кар & 640 & 62.13 & 0.0621 & & $2.44 \mathrm{E}+06$ & 0.0387 & 0.0621 \\
\hline & 25 & 50\%TFE 50\% Kap & 640 & 25.73 & 0.0257 & $Y$ & $2.04 E+06$ & 0.0160 & 0.0257 \\
\hline & 26 & $100 \%$ Kapton & 640 & 9.19 & 0.0092 & & $2.24 \mathrm{E}+06$ & 0.0057 & 0.0092 \\
\hline & 27 & Circuit Bd & 340 & 110.96 & 0.1110 & $Y$ & $3.80 E+06$ & 0.0691 & 0.1110 \\
\hline & 28 & Std Mix & 430 & 96.95 & 0.0969 & $Y$ & $2.35 \mathrm{E}+06$ & 0.0604 & 0.0969 \\
\hline & 29 & wire insulation & 640 & 16.83 & 0.0168 & $Y$ & $2.85 E+06$ & 0.0105 & 0.0168 \\
\hline & 30 & $100 \%$ TFE & 640 & 10.78 & 0.0108 & & $1.71 E+06$ & 0.0067 & 0.0108 \\
\hline & 31 & wire insulation & 640 & 11.68 & 0.0117 & & $2.21 \mathrm{E}+06$ & 0.0073 & 0.0117 \\
\hline Day 3 & 32 & 75\%TFE 25\%Kap & 640 & 24.09 & 0.0241 & & $2.01 \mathrm{E}+06$ & 0.0150 & 0.0241 \\
\hline \multirow[t]{10}{*}{$3 / 1 / 2012$} & 33 & Std Mix & 340 & 131.31 & 0.1313 & & $4.27 \mathrm{E}+06$ & 0.0818 & 0.1313 \\
\hline & 34 & Circuit Bd & 430 & 95.82 & 0.0958 & & $2.83 E+06$ & 0.0597 & 0.0958 \\
\hline & 35 & wire insulation & 540 & 11.08 & 0.0111 & Y & $2.87 E+06$ & 0.0069 & 0.0111 \\
\hline & 36 & $90 \%$ TFE $10 \%$ Kap & 640 & 71.28 & 0.0713 & $Y$ & $3.57 E+06$ & 0.0444 & 0.0713 \\
\hline & 37 & 10\%TFE $90 \%$ Кар & 640 & 29.57 & 0.0296 & & $2.16 E+06$ & 0.0184 & 0.0296 \\
\hline & 38 & 25\%TFE $75 \%$ Kap & 640 & 21.91 & 0.0219 & Y & $1.62 E+06$ & 0.0136 & 0.0219 \\
\hline & 39 & Std Mix & 640 & 49.61 & 0.0496 & & $3.02 E+06$ & 0.0309 & 0.0496 \\
\hline & 40 & $100 \%$ Kapton & 540 & 2.40 & 0.0024 & & $1.26 \mathrm{E}+06$ & 0.0015 & 0.0024 \\
\hline & 41 & $100 \%$ Kapton & 540 & 7.21 & 0.0072 & & $1.85 E+06$ & 0.0045 & 0.0072 \\
\hline & 42 & $100 \%$ TFE & 640 & 12.96 & 0.0130 & $Y$ & $1.45 E+06$ & 0.0081 & 0.0130 \\
\hline Day 4 & 43 & 25\%TFE 75\%Кар & 540 & 44.92 & 0.0449 & & $2.39 E+06$ & 0.0280 & 0.0449 \\
\hline
\end{tabular}

23

American Institute of Aeronautics and Astronautics 
Appendix F. Particle mass concentration and ash data for the Sep 2012 Test

Note: Grey cells denote anomaly due to run sequence error or inadvertent self-ignition; omit from averages, or no data available for this test. No aerosol mass concentration data collected for runs 59-62

\begin{tabular}{|c|c|c|c|c|c|c|c|c|c|c|c|}
\hline $\begin{array}{l}\text { Sep } 2012 \\
\text { TestDates }\end{array}$ & $\begin{array}{l}\text { Test } \\
\text { No. }\end{array}$ & Material & $\begin{array}{l}\text { TEOM Mass } \\
\text { Conc } \mathrm{g} / \mathrm{m}^{\wedge} 3\end{array}$ & $\begin{array}{l}\text { Avg Mass } \\
\text { Conc, } g / \mathrm{m}^{\wedge} 3\end{array}$ & $\begin{array}{l}\text { standard } \\
\operatorname{dev}, g / m^{\wedge} 3\end{array}$ & $\begin{array}{c}\text { Aerosol Mass } \\
\text { Fraction below } \\
1 \mu \mathrm{m}\end{array}$ & \begin{tabular}{|c|} 
Aerosol \\
Number \\
Concentration, \\
\end{tabular} & $\begin{array}{c}\text { Avg Number } \\
\text { Conc, } \\
\# / \mathrm{cm}^{\wedge} 3\end{array}$ & $\begin{array}{c}\text { standard dev, } \\
\# / \mathrm{cm}^{\wedge} 3\end{array}$ & $\begin{array}{l}\text { Est mass of } \\
\text { particles, } g\end{array}$ & $\begin{array}{c}\text { Ash Mass } \\
(\mathrm{g})\end{array}$ \\
\hline \multirow[t]{5}{*}{$9 / 10 / 2012$} & 1 & NOMEX & 0.0774 & & & & & & & 0.0482 & 0.028 \\
\hline & 2 & $"$ & 0.0440 & TP & ? & & $4.82 \mathrm{E}+06$ & & & 0.0274 & 0.046 \\
\hline & 3 & $"$ & 0.0718 & & & & $4.52 E+06$ & & & 0.0447 & 0.045 \\
\hline & 4 & $"$ & 0.0647 & & & & $4.85 E+06$ & & & 0.0403 & 0.014 \\
\hline & 5 & $"$ & 0.0727 & & & & $4.55 E+06$ & & & 0.0453 & 0.042 \\
\hline Day 1 & 6 & $"$ & 0.0639 & (omit from avg) & & & $5.62 \mathrm{E}+06$ & & & 0.0398 & 0.153 \\
\hline \multirow[t]{17}{*}{$9 / 11 / 2012$} & 7 & $"$ & 0.0622 & TP & & & $5.72 E+06$ & & & 0.0387 & 0.091 \\
\hline & & average \& st dev & & 0.0655 & 0.0119 & & & $4.89 \mathrm{E}+06$ & $4.87 \mathrm{E}+05$ & 0.0408 & 0.044 \\
\hline & 8 & wire insulation & 0.0705 & (omit from avg) & & & $5.95 E+06$ & & & & 0.046 \\
\hline & 9 & $"$ & 0.0559 & & & & $4.29 E+06$ & & & 0.0348 & 0.021 \\
\hline & 10 & $"$ & 0.0435 & & & & 4.07E+06 & & & 0.0271 & 0.017 \\
\hline & 11 & $"$ & 0.0493 & & & & $3.96 \mathrm{E}+06$ & & & 0.0307 & 0.021 \\
\hline & 12 & $"$ & 0.0478 & & & & $4.29 E+06$ & & & 0.0297 & 0.030 \\
\hline & 13 & $"$ & 0.0542 & & & & $3.91 \mathrm{E}+06$ & & & 0.0337 & 0.017 \\
\hline & & average \& st dev & & 0.0501 & 0.0050 & & & $4.10 \mathrm{E}+06$ & $1.78 \mathrm{E}+05$ & 0.0312 & 0.021 \\
\hline & 14 & $100 \%$ PTFE & 0.0367 & & & 1 & $4.28 \mathrm{E}+06$ & & & 0.0229 & 0.041 \\
\hline & 15 & $"$ & 0.0335 & & & 0.994 & $4.84 \mathrm{E}+06$ & & & 0.0209 & 0.014 \\
\hline & 16 & $"$ & 0.0344 & & & 1 & $3.25 E+06$ & & & 0.0214 & 0.010 \\
\hline & 17 & $"$ & 0.0503 & & & 0.988 & $2.52 E+06$ & & & 0.0313 & 0.015 \\
\hline & & average \& st dev & & 0.0387 & 0.0078 & & & $3.73 \mathrm{E}+06$ & $1.04 \mathrm{E}+06$ & 0.0241 & 0.020 \\
\hline & 18 & kapton squares & 0.0049 & & & 0.993 & $2.90 E+06$ & & & 0.0031 & 0.227 \\
\hline & 19 & " & 0.0024 & & & 0.996 & $2.94 \mathrm{E}+06$ & & & 0.0015 & 0.278 \\
\hline & 20 & $"$ & 0.0036 & & & 1 & $3.01 E+06$ & & & 0.0022 & 0.251 \\
\hline Day 2 & & average \& st dev & & 0.0036 & 0.0013 & & & $2.95 \mathrm{E}+06$ & $5.58 \mathrm{E}+04$ & 0.0023 & 0.252 \\
\hline \multirow[t]{21}{*}{$9 / 12 / 2012$} & 21 & granulated kapton & 0.0179 & & & 0.982 & $4.41 E+06$ & & & 0.0112 & 0.126 \\
\hline & 22 & $"$ & 0.0194 & & & 0.984 & $4.32 \mathrm{E}+06$ & & & 0.0121 & 0.112 \\
\hline & & average \& st dev & & 0.0187 & 0.0011 & & & $4.36 \mathrm{E}+06$ & $6.13 \mathrm{E}+04$ & 0.0116 & 0.119 \\
\hline & 23 & PTFE powder (100 um) & 0.0173 & $\overline{\text { (omit from avg) }}$ & & 0.982 & $3.30 E+06$ & & & & 0 \\
\hline & 24 & $"$ & 0.0550 & & & 0.999 & $5.20 \mathrm{E}+06$ & & & 0.0343 & 0.006 \\
\hline & 25 & $"$ & no data & & & 0.998 & $4.96 E+06$ & & & no data & 0.008 \\
\hline & 26 & $"$ & 0.0516 & & & 0.997 & $4.98 \mathrm{E}+06$ & & & 0.0321 & 0.009 \\
\hline & & average \& st dev & & 0.0533 & 0.0024 & & & $5.05 \mathrm{E}+06$ & $1.32 \mathrm{E}+05$ & 0.0332 & 0.008 \\
\hline & 27 & 340 PCB & 0.0557 & & & 0.936 & $4.00 E+06$ & & & 0.0347 & 0.366 \\
\hline & 28 & $"$ & 0.0651 & TP & & 0.928 & $4.12 \mathrm{E}+06$ & & & 0.0406 & 0.352 \\
\hline & & average \& st dev & & 0.0604 & 0.0066 & & & $4.06 \mathrm{E}+06$ & $8.33 \mathrm{E}+04$ & 0.0376 & 0.359 \\
\hline & 29 & 440 PCB & 0.0580 & & & 0.922 & $5.43 E+06$ & & & 0.0361 & 0.344 \\
\hline & 30 & $"$ & 0.0742 & TP & ד & 0.922 & $5.35 \mathrm{E}+06$ & & & 0.0462 & 0.323 \\
\hline & & average \& st dev & & 0.0661 & 0.0115 & & & $5.39 \mathrm{E}+06$ & $5.58 \mathrm{E}+04$ & 0.0412 & 0.334 \\
\hline & 31 & 540 PCB & 0.0885 & TP & & 0.922 & $6.20 E+06$ & & & 0.0551 & 0.321 \\
\hline & 32 & $"$ & 0.0885 & & & 0.923 & $5.88 \mathrm{E}+06$ & & & 0.0551 & 0.335 \\
\hline & & average \& st dev & & 0.0885 & 0.0000 & & & $6.04 \mathrm{E}+06$ & $2.25 \mathrm{E}+05$ & 0.0551 & 0.328 \\
\hline & 33 & 640 PCB & 0.1070 & TP & & 0.926 & $6.66 \mathrm{E}+06$ & & & 0.0667 & 0.308 \\
\hline & 34 & $"$ & 0.1110 & & & 0.911 & $6.32 \mathrm{E}+06$ & & & 0.0692 & 0.302 \\
\hline & & average \& st dev & & 0.1090 & 0.0028 & & & $6.49 \mathrm{E}+06$ & $2.43 \mathrm{E}+05$ & 0.0679 & 0.305 \\
\hline & 35 & PVC & 0.1150 & & & 0.893 & $6.11 E+06$ & & & 0.0716 & 0.009 \\
\hline Day 3 & & & & 0.1150 & & & & $6.11 \mathrm{E}+06$ & & & \\
\hline
\end{tabular}


Appendix F. continued...

\begin{tabular}{|c|c|c|c|c|c|c|c|c|c|c|c|}
\hline \multirow[t]{26}{*}{$9 / 13 / 2012$} & 36 & 50-50 teflon/kapton & 0.0358 & & & 0.993 & $4.36 E+06$ & & & 0.0223 & 0.046 \\
\hline & 37 & (100 um teflon powder/ & 0.0252 & & & 0.988 & $3.82 E+06$ & & & 0.0157 & 0.061 \\
\hline & 38 & granulated kapton) & 0.0364 & (omit from avg) & & 0.993 & $4.03 E+06$ & & & & 0.111 \\
\hline & 39 & $"$ & 0.0394 & & & 0.995 & $3.95 E+06$ & & & 0.0245 & 0.042 \\
\hline & & average \& st dev & & 0.0334 & 0.0074 & & & $4.04 \mathrm{E}+06$ & $2.83 E+05$ & 0.0208 & 0.050 \\
\hline & 40 & 25-75 teflon/kapton & 0.0284 & & & 0.994 & $3.81 E+06$ & & & 0.0177 & 0.092 \\
\hline & 41 & (100 um teflon powder/ & 0.0254 & & & 0.991 & $3.75 E+06$ & & & 0.0158 & 0.074 \\
\hline & 42 & granulated kapton) & 0.0252 & & & 0.988 & $3.66 \mathrm{E}+06$ & & & 0.0157 & 0.128 \\
\hline & 43 & $"$ & 0.0270 & & & 0.993 & $3.55 E+06$ & & & 0.0168 & 0.074 \\
\hline & & average \& st dev & & 0.0265 & 0.0015 & & & $3.69 \mathrm{E}+06$ & $1.16 \mathrm{E}+05$ & 0.0165 & 0.080 \\
\hline & 44 & 10-90 teflon/kapton & 0.0129 & & & 0.996 & $3.29 E+06$ & & & 0.0080 & 0.088 \\
\hline & 45 & (100 um teflon powder/ & 0.0140 & (omit from avg) & & 0.988 & $3.30 E+06$ & & & & 0.139 \\
\hline & 46 & granulated kapton) & 0.0117 & & & 0.993 & $3.76 E+06$ & & & 0.0073 & 0.088 \\
\hline & & average \& st dev & & 0.0123 & 0.0008 & & & $3.52 \mathrm{E}+06$ & $3.33 \mathrm{E}+05$ & 0.0076 & 0.088 \\
\hline & 47 & $75-25$ teflon/kapton & 0.0498 & & & 0.996 & $3.18 \mathrm{E}+06$ & & & 0.0310 & 0.031 \\
\hline & 48 & (100 um teflon powder/ & 0.0250 & (omit from avg) & & 0.977 & $3.68 \mathrm{E}+06$ & & & & 0.047 \\
\hline & 49 & granulated kapton) & 0.0440 & & & 0.996 & $3.80 E+06$ & & & 0.0274 & 0.011 \\
\hline & 50 & $"$ & 0.0512 & & & 0.996 & $3.29 E+06$ & & & 0.0319 & 0.021 \\
\hline & & average \& st dev & & 0.0483 & 0.0038 & & & $3.42 \mathrm{E}+06$ & $3.33 \mathrm{E}+05$ & 0.0301 & 0.021 \\
\hline & 51 & 90-10 teflon/kapton & 0.0171 & & & 1 & $3.19 E+06$ & & & 0.0106 & 0.016 \\
\hline & 52 & (100 um teflon powder/ & 0.0349 & & & 0.997 & $3.48 \mathrm{E}+06$ & & & 0.0218 & 0.007 \\
\hline & 53 & granulated kapton) & 0.0378 & $0.0364^{\circ}$ & 0.0020 & 0.995 & $3.93 E+06$ & & & outlier (\#51. & 0.010 \\
\hline & & average $\&$ st dev & & 0.0299 & 0.0112 & & & $3.54 \mathrm{E}+06$ & $3.71 \mathrm{E}+05$ & 0.0187 & 0.011 \\
\hline & 54 & $90-10$ teflon/PVC & 0.1113 & & & 0.969 & $4.33 E+06$ & & & 0.0693 & 0.002 \\
\hline & 55 & (100 um teflon powder/ & 0.1386 & & & 0.944 & $4.35 E+06$ & & & 0.0863 & 0.002 \\
\hline & 56 & granulated PVC) & 0.1301 & & & 0.945 & $5.97 E+06$ & & & 0.0810 & 0.001 \\
\hline Day 4 & & average \& st dev & & $0.1343^{\circ}$ & 0.0060 & & & $4.88 \mathrm{E}+06$ & $9.42 \mathrm{E}+05$ & 0.0837 & 0.002 \\
\hline \multirow[t]{6}{*}{ 9/14/2012 } & 57 & PCB+PVC1 & 0.0497 & & & & $5.99 E+06$ & & & & \\
\hline & 58 & $"$ & 0.1110 & & & & $5.88 E+06$ & & & & \\
\hline & 59 & $"$ & & & & & $5.82 E+06$ & & & & \\
\hline & & average \& st dev & & 0.1110 & 0.0433 & & & $5.90 \mathrm{E}+06$ & $8.62 \mathrm{E}+04$ & & \\
\hline & 60 & $\mathrm{PCB}+\mathrm{PVC} 2$ & & & & & $5.83 E+06$ & & & & \\
\hline & 61 & $"$ & & & & & $4.66 \mathrm{E}+06$ & & & & \\
\hline Day 5 & & average \& st dev & & & & & & $5.25 \mathrm{E}+06$ & $8.23 E+05$ & & \\
\hline
\end{tabular}

\section{Acknowledgments}

Certain commercial entities, equipment, or materials may be identified in this document in order to describe an experimental procedure or concept adequately. Such identification is not intended to imply recommendation or endorsement by the National Aeronautics and Space Administration, nor is it intended to imply that the entities, materials, or equipment are necessarily the best available for the purpose.

\section{References}

1. Ruff, G. A., Greenberg, P. S., Mudgett, P. D., Hornung, S. D., Pilgrim, J. S., Vakhtin, A. B, "Towards the Ientification of Chemical Markers for Spacecraft Post-fire Cleanup," $41^{\text {st }}$ International Conference On Environmental Systems, SAE, Portland, OR, 17-21 July 2011, AIAA 2011-5052.

2. Sribnik,F., Birbara, P.J., Faszcza, J. J., and Nalette, T. A., "Smoke and Contaminant Removal System for Space Station," SAE Paper 901390, $20^{\text {th }}$ Intersociety Conference on Environmental Systems, Williamsburg, VA, July 9-12, 1990.

3. Pilgrim, Jeffrey S. “Advanced Fire Detector for Space Applications," NASA Tech Briefs, 36, No. 6 (2012), 90.

4. Pilgrim, Jeffrey S. "Rugged, Portable, Real-Time Optical Gaseous Analyzer for Hydrogen Fluoride," NASA Tech Briefs, 36, No. 10, (2012), 25.

5. Hunter, G. W., Xu, J. C., Biaggi-Labiosa, A. M., Ward, B., Dutta, P., and Liu, C. C., "Smart Sensor System for Spacecraft Fire Detection and Air Quality Monitoring," $41^{\text {st }}$ International Conference On Environmental Systems, SAE, Portland, OR, 17-21 July 2011, AIAA 2011-5021.

6. Hunter, G. W., Greenberg, P. S., Xu, J. C., Ward, B., Makel, D., Dutta, P., and Liu, C. C., "Miniaturized Sensor Systems for Early Fire Detection in Spacecraft," $39^{\text {th }}$ International Conference On Environmental Systems, SAE, Warrendale, PA, 12-16 July 2009, 09ICES-0335. 